\title{
THE CHALLENGE OF OLFACTORY IDEOPHONES: RECONSIDERING INEFFABILITY FROM THE TOTONAC-TEPEHUA PERSPECTIVE ${ }^{1}$
}

\section{Carolyn O'Meara}

National Autonomous University of Mexico
Susan Smythe Kung

University of TeXas at Austin

\section{AsIFA MAJID}

UNIVERSITY OF YORK

\begin{abstract}
Olfactory impressions are said to be ineffable, but little systematic exploration has been done to substantiate this. We explored olfactory language in Huehuetla Tepehua-a TotonacTepehua language spoken in Hidalgo, Mexico-which has a large inventory of ideophones, words with sound-symbolic properties used to describe perceptuomotor experiences. A multi-method study found Huehuetla Tepehua has 45 olfactory ideophones, illustrating intriguing sound-symbolic alternation patterns. Elaboration in the olfactory domain is not unique to this language; related Totonac-Tepehua languages also have impressive smell lexicons. Comparison across these languages shows olfactory and gustatory terms overlap in interesting ways, mirroring the physiology of smelling and tasting. However, although cognate taste terms are formally similar, olfactory terms are less so. We suggest the relative instability of smell vocabulary in comparison with those of taste likely results from the more varied olfactory experiences caused by the mutability of smells in different environments.
\end{abstract}

[KEYwORDs: Ideophones, Tepehua, Totonac, olfaction, depiction, comparative method]

${ }^{1}$ This project was jointly conceived by the three authors as part of the NWO VICI "Human Olfaction at the Intersection of Language, Culture, and Biology" project 277-70-011 (PI Majid), which also provided funding. Novel data were collected by O'Meara and Kung in August 2014 in Huehuetla, Hidalgo, Mexico. Kung provided further invaluable expertise on Huehuetla Tepehua gleaned from years of prior research. All authors contributed to the writing of the paper, with O'Meara taking the lead role. We are immensely grateful to the native speakers of Huehuetla Tepehua who took the time and energy to share their language with us, including Alicia Granillo Apolonio, Angelita García Vigueras, Catalina Vigueras Gutierrez, Dolores Alejandro Santiago, Fidela Sevilla García, Fidela Tolentino Huerta, Feliza Eologio Huerta, Ignacia Mina Vigueras, Isabel Huerta Santiago, José Tolentino Alejandro, Juana García Alejandro, Juana Gutierrez Patricio, Laurencio Vigueras Patricio, Lola García Santiago, Lola Santiago Cristobal, Lucia Quintero Primo, Magdalena García Encarnación, Miguel Vigueras Patricio, Nicolás Vigueras Patricio, and Teresa Crecencio Dominguez. All uncited Huehuetla Tepehua data in this paper are taken from the recordings and notes made by O'Meara and Kung during the fieldwork described herein; notes and recordings are archived at the Archive of the Indigenous Languages of Latin America (AILLA) under record number 255668 and may be freely accessed and used according to AILLA's user guidelines (https://www.ailla.utexas.org/). We are grateful to David Beck, Carolyn MacKay, and Paulette Levy for sharing unpublished data with us and to Mark Dingemanse and members of the Meaning, Culture, and Cognition group for their helpful comments.

[IJAL, vol. 85, no. 2, April 2019, pp. 173-212]

(C) 2019 by The University of Chicago. All rights reserved.

0020-7071/2019/8502-0001\$10.00 DOI 10.1086/70180 
1. Introduction. It has long been said that olfaction is ineffable- that is, impossible to put into words (e.g., Henning 1916; Sperber 1975; Levinson and Majid 2014; Olofsson and Gottfried 2015) —but studies show some languages have elaborate lexicons for smell (e.g., Hombert 1992; van Beek 1992; Burenhult and Majid 2011; Tufvesson 2011; Storch 2013, 2014; Wnuk and Majid 2014; O'Meara and Majid 2016). One of the first articles to illustrate a lexical field in the domain of olfaction did so for Sierra Totonac, a language spoken in eastern Mexico (Aschmann 1946). This lexical domain was further elaborated in Aschmann's dictionary of Sierra Totonac, which contains 23 different adjective entries under the Spanish infinitive oler 'to smell' (2000:137-38). Aschmann's (1946) paper was also intriguing in that he showed a special kind of linguistic coding of olfactory concepts that utilized sound-symbolic phonemic alternations to represent changes in odor qualities. This process of using sound-symbolic phonemic alternations to represent changes in meaning is exploited throughout the Totonac-Tepehua language family (McQuown 1990 [1940]; Aschmann 1983; Bishop 1984; Levy 1987; Watters 1988; MacKay 1999; Beck 2004; Kung 2007), and, as we will show, it is especially prevalent in the olfactory domain. Notably, sound-symbolic alternations are frequently found in ideophones in these languages (Kung 2005, 2006a, 2006b, 2007; Beck 2007, 2008; McFarland 2010).

Ideophones-which have also been called expressives, mimetics, soundsymbolic words, and affect words, among other terms - are words with soundsymbolic properties used to describe perceptuomotor experiences (Doke 1935; Kaufman 1988; Kulemeka 1995; Voeltz and Kilian-Hatz 2001; England 2004; Dingemanse 2012; Dingemanse et al. 2015). Dingemanse (2011:25) has proposed the following definition: "marked words that depict sensory imagery." For example, in Upper Necaxa Totonac, kimkimkim is an ideophone used to indicate the way a firefly flashes repeatedly, and tsanana, the buzzing sound of insects (Beck 2008). It has been suggested that sensorial experiences in particular lead to iconic form-to-meaning mappings cross-linguistically (Perniss et al. 2010). Such mappings involve perceived resemblance between the sign and the object, which can be observed in examples of vowel lengthening to indicate extent (e.g., a loooong time ago), or reduplication to indicate repetition or pluralization (e.g., in Tohono O'odham, gogs 'dog' and gogogs 'dogs'; Hill and Zepeda 1992:386). However, ideophones show different degrees of iconicity, and in more recent studies they have been characterized by their depictive nature, and only secondarily as iconic (Dingemanse 2012).

Doke (1935), who established the classic definition of the term ideophone in his book of Bantu terminology, specifically mentions smell as one of the qualities that ideophones are likely to indicate. This is surprising because smell is considered ineffable to this day. To dispel this prevailing view, the present paper presents a case study of olfactory terms, many of which are ideophones, and explores what Totonac-Tepehua languages have to tell us about ideophones and olfactory language more generally. 
Our case study focuses on Huehuetla Tepehua. At first glance, Huehuetla Tepehua seemed compatible with claims of the ineffability of olfaction since initial exploration suggested scant vocabulary in this domain, but targeted elicitation using a multi-method approach revealed an elaborate lexical field of smell. We found Huehuetla Tepehua has more than 40 odor terms, some of which are ideophones. At the same time, although we uncover an extensive repertoire of odor terms in the language, including various ideophones, we find their semantic properties differ in interesting ways from other ideophones in Huehuetla Tepehua. Olfactory ideophones are not as transparent in their sensory profiles. The implications of this are far-reaching: theories of ideophones (e.g., Dingemanse 2011) not only need to be revised to include the distal modalities of vision and sight but must also include in their purview the less-described perceptual modalities.

Finally, by comparing related olfactory terms across Totonac-Tepehua languages we take a comparative-historical perspective and show that olfactory terms have longevity, as evidenced by the large number of cognates. This finding proves problematic for claims of ineffability in the olfactory domain and its presumed ephemerality, and it raises questions regarding the durability of ideophones (Lanham 1960, as cited in Childs 1994). Interestingly, although forms remain stable, meanings appear more malleable, suggesting olfactory semantics change to reflect local ecologies more than terms from other perceptual domains.

1.1. The ineffability of smell reconsidered. Olfaction has generally been considered ineffable, a domain that is not linguistically coded (Levinson and Majid 2014), and cross-linguistically rara (Plank and Filimonova 2000). Psychological studies have shown that people struggle to name odors under controlled experimental situations. When given the smell of cinnamon in one study, for example, English speakers said it smelled of bayberry, candy, Red Hot, smoky, spicy, sweet, edible, wine, potpourri, as well as of cinnamon (Majid and Burenhult 2014:270). In fact, of the ten people asked, nine different descriptions were given. In addition, when odor-related words are read (silently), olfactory representations are not accessed in the same way that, for example, auditory representations are accessed from soundrelated words (Speed and Majid 2018), and some neuroscientists conclude accordingly that olfactory and language areas are not well connected (Olofsson and Gottfried 2015).

At the same time, evidence that languages can have elaborated smell lexicons is accumulating (e.g., Hombert 1992; van Beek 1992; Blench and Longtau 1995; Storch and Vossen 2006; Lee 2014; Majid and Burenhult 2014; Wnuk and Majid 2014; Majid 2015; O'Meara and Majid 2016; Majid and Kruspe 2018). This increasing interest in the topic means that field linguists are turning to their own records to discover whether the language they study is hiding its olfactory potential under a bushel. Sometimes such perusals 
return little of interest. However, we show in our case study here that specific elicitation methods can uncover hidden gems that challenge the long-held notion of ineffability in olfaction.

When it comes to eliciting sensory language, auditory, visual, and tactile experiences are easier to enact and, as such, elicit (Ratliff 1992; Voeltz and Kilian-Hatz 2001; Tufvesson 2007). However, olfactory and gustatory experiences typically have not been targeted in this way as a part of the standard battery of language description tasks (see, however, Majid 2007; Majid et al. 2018). Using Sniffin' Sticks as an elicitation method (see 2.2), we revisited the lexicon of sensory experiences in Huehuetla Tepehua with a specific focus on olfactory language. This lexical domain in Huehuetla Tepehua contains many ideophones, whose morphophonological markedness and semantic specificity provide additional complexity for linguists seeking elicitation methods to document language (e.g., Samarin 1967; Mithun 1982; Blench 2010).

1.2. Semantics of ideophones and the challenge from olfaction. The fact that some languages have attested olfactory lexicons while others do not raises the broader question of what sorts of linguistic strategies are available for referring to odors cross-linguistically. One common strategy for naming odors is to use nouns (or derived adjectives such as lemony or chocolatey) that refer to a specific source (e.g., it smells like banana, rose, tar, etc.). This appears to be the default mode for Standard Average European languages. Another strategy is the use of verbs. This is attested in the Aslian languages of the Malay Peninsula, for example, where elaborate lexical fields for smell are predominantly expressed as stative verbs (e.g., Burenhult and Majid 2011; Majid and Burenhult 2014; Wnuk and Majid 2014). In these languages, the smell vocabulary is said to be "basic" (cf. Berlin and Kay 1969) since the terms referring to abstract odor qualities are not related to any specific odor source (Burenhult and Majid 2011). In the African context, a number of studies suggest smell terminology is "ideophone-like." However, the morpho-syntactic properties of smell terms in these languages do not fit into the attested word classes, and they have been argued to be a distinct class of their own (Blench and Longtau 1995; Storch 2004; Blench 2010).

In this context it is particularly interesting to consider olfactory ideophones in more detail. Studies of ideophones have paid less attention to the semantics and use of such terms in naturally occurring speech, focusing instead on their structural properties (Dingemanse 2012; although see Childs 1994; Chapman 1996; Smoll 2015; Henderson 2016; Lee 2017). The marked behavior of ideophones morphologically and phonologically, in addition to their rich referential qualities, has posed considerable problems for lexicographers (Beck 2008). Observations of ideophone semantics tend to express generalizations, such as: ideophones convey rich and specific meanings concisely (see, for example, Samarin 1967; Beck 2008; Dingemanse 2011, 2012). Dingemanse (2011:228) 
has linked the semantic specificity of ideophones to the fact that they are depictive of sensory imagery. Depiction in ideophones has been described as "a performance, inviting us to 'look' in such a way that we make believe we are actually experiencing the scene depicted" (Dingemanse 2012:655). Similarly, ideophones in Pastaza Quichua have been described as differing from other adverbs in the language in that they involve performative simulation (Nuckolls 2010). With depiction—as opposed to description-people "mainly rely on their visual, auditory, tactile, and proprioceptive knowledge of physical scenes and on their ability to use one scene in imagining another" (Clark 2016:324). For instance, one type of depiction could be someone saying "this long" while gesturing with their hands to indicate the exact length: the co-speech gesture, then, depicts length.

It is presently not clear whether the semantics of olfactory ideophones more closely resemble those found in nouns or verbs, or if they express a different meaning complex altogether (i.e., whether they are "depictive"). There are only a handful of previous studies describing high levels of semantic elaboration in the olfactory domain by means of ideophones. In Semai, an Aslian language spoken in Malaysia, 15 of its 25 smell terms adhere to language-specific ideophone templates. The basic template appears to encode a particular type of odor quality, while vowel alternations modify the odor intensity or quality (Tufvesson 2011; see also Svantesson 2017 on Kammu). This semantic model appears to have wider applicability, as we will show in $\mathbf{2}$ in the context of olfactory terms in Huehuetla Tepehua, as well as Totonac (Aschmann 1946, 2000; Enríquez Andrade 2004, 2010; Santiago Francisco 2009), which we come back to in more detail in $\mathbf{3}$. Given the claimed limitations of encoding olfaction, characterizing olfactory language in more detail is important to a future typology of olfactory terms, as well as to the understanding of ideophone semantics more generally.

1.3. Further insights on olfactory terminology from a comparative perspective. If olfactory language is poor, as is presumed, then we certainly would not expect it to have much longevity. This would seem to hold in particular for olfactory ideophones. Compared with non-ideophonic words, ideophones have been said to be replaced at a faster rate (Lanham 1960, as cited in Childs 1994): speakers can employ language-specific means to easily coin new ideophones, and these, in turn, are effortlessly understood by hearers, given the systematic ways sounds are mapped to meanings within this word class. This adaptability and fluidity suggests there would be fast turnover of ideophones, and as such, less stability in cognate terms across related languages. However, very few studies have attempted to examine cognate ideophone forms across related languages, although Blench (2010:274) indicates that ideophones tend not to be cognates lexically. Here we present one of the first comparative studies of meanings 
expressed by ideophones by exploring the olfactory and gustatory domains within languages from the Totonac-Tepehua language family, which contain many ideophones.

We show terms of olfaction and gustation occasionally overlap in interesting ways, mirroring the physiology of smelling and tasting. Nevertheless, it is possible to delimit these domains. When we do so, we see cognate taste terms are formally relatively similar across these languages, but this is less so for olfactory lexemes. The instability of olfactory terms across languages could have its roots in the pan-human "weak link" between olfaction and language (Rivlin and Gravelle 1984; Olofsson and Gottfried 2015). We propose, instead, that the relative stability of taste terms and concomitant variation in olfactory terms is actually the result of the uniformity of taste vs. olfactory experiences caused by the mutability of smells in different environments.

Before turning to the comparative historical data in $\mathbf{3}$, we first focus in detail on one language in particular, Hueuelta Tepehua. In 2, we demonstrate that Huehuelta Tepehua has a rich repertoire of olfactory terms, many of which are ideophones, by presenting novel data elicited using sensory materials. To provide the necessary backdrop, we begin by presenting some general information about Huehuetla Tepehua, and the basic characteristics of ideophones in this language (2.1). We then describe a method for eliciting olfactory ideophones in the field (2.2) and explore the meaning of olfactory terms, in particular their intriguing sound-symbolic alternation patterns and what they might indicate about olfactory semantics in general (2.3).

2. Odor terms in Huehuetla Tepehua. Huehuetla Tepehua (ISO code: tee) is spoken in the state of Hidalgo, located in the eastern Sierra Madre in the Central Gulf Coast region of Mexico. The town of Huehuetla is the seat of the municipality of the same name. Huehuetla Tepehua is part of the Totonac-Tepehua language family that Campbell, Kaufman, and Smith-Stark (1986) describe as an isolate family in Mesoamerica, but that Brown et al. (2011) classify as belonging to the Totozoquean language family, which includes the Mixe-Zoquean language family as well. Census data (INEGI 2005) reports 1,794 speakers of Huehuetla Tepehua. Similarly, Kung (2007) reports fewer than 1,500 speakers of this variety, which she has described as a moribund language no longer actively transmitted to children, and with almost no monolingual speakers left. Spanish, the dominant language of Mexico, is quickly taking over in the town of Huehuetla as the preferred language of daily communication.

Huehuetla Tepehua is a polysynthetic head-marking language with complex verbal morphology in which verbal inflection is marked by both prefixes and suffixes (Kung 2007:23). The constituent order is pragmatically determined, but there is a tendency toward VSO word order when there are no 
TABLE 1

Consonant Inventory of Huehuetla Tepehua (Kung 2007:30)

\begin{tabular}{|c|c|c|c|c|c|c|c|c|}
\hline & Bilabial & Alveolar & Lateral & $\begin{array}{l}\text { Palato- } \\
\text { Alveolar }\end{array}$ & Palatal & Velar & Uvular & Glottal \\
\hline Stop & $\mathrm{p}$ & $\mathrm{t}$ & & & & $\mathrm{k}$ & $* \mathrm{q}$ & \\
\hline Glottalized Stop & p' & $t^{\prime}$ & & & & $\mathrm{k}^{\prime}$ & *q' & ? \\
\hline Nasal & $\mathrm{m}$ & $\mathrm{n}$ & & & & & & \\
\hline Fricative & & $\mathrm{s}$ & 1 & $\int$ & & & & \\
\hline Affricate & & ts & & t $\int$ & & & & \\
\hline \multicolumn{9}{|l|}{ Glottalized } \\
\hline Affricate & & $\widehat{t s}^{\prime}$ & & $\widehat{t 5}$ & & & & \\
\hline Liquid & & & 1 & & & & & \\
\hline Trill \& & & $\mathrm{r}$ & & & & & & \\
\hline Flap & & r & & & & & & \\
\hline Approximant & w & & & & $\mathrm{j}$ & & & $\mathrm{h}$ \\
\hline
\end{tabular}

contextual clues to indicate preferred participant roles (such as animacy and cultural relevance), and SVO when there are (Kung 2007:ix). In addition to having verbs and nouns, Huehuetla Tepehua also has classes of adjectives and adverbs, some of which manifest themselves as full words, and others as particles (Kung 2007:24).

2.1. Ideophones and sound symbolism in Huehuetla Tepehua. Ideophones in Huehuetla Tepehua are a subclass of manner adverbs, which have both ideophonic and non-ideophonic forms (Kung 2005, 2007). Adverbs are distinguished from nouns, verbs, and adjectives in that they are never inflected, they always precede the verb, and they frequently occur with light verbs. In addition, ideophones show marked behavior when it comes to stress and vowel devoicing. Our focus is olfactory terms, but Kung (2005, 2006a, 2006b) describes the types of sounds, actions, and sensations that are also encoded in Huehuetla Tepehua ideophones. We first provide information regarding the relevant characteristics of ideophones in Huehuetla Tepehua to illustrate how they differ from non-ideophonic words.

In order to understand how ideophones compare with the rest of the lexicon, we start by presenting some basic phonological facts (tables 1 and 2). Huehuetla Tepehua has 20 native consonants, with two additional consonants found only in ideophones $(/ \mathrm{r} /, / \mathrm{r} /)$ and three consonants found in Spanish loanwords (/b/, /d/, /g/) or in allophonic distribution to their voiceless counterparts (Kung 2007:30). Note that all stops and affricates have both plain and glottalized versions, and that the plain and glottalized uvular stops have recently merged with the glottal stop (Smythe 2003; Kung 2007).

Huehuetla Tepehua has a five-vowel system (table 2). Tepehua vowels pattern like the rest of the language family in that vowel length is contrastive; 
TABLE 2

Vowel Inventory of Huehuetla Tepehua

(KUNG 2007:32)

\begin{tabular}{llll}
\hline \hline & Front & Central & Back \\
\hline High & i, i: & & u, u: \\
Mid & e, e: & & o, o: \\
Low & & a, a: & \\
\hline
\end{tabular}

however, unlike the Totonac branch of the family, vowel laryngealization is not contrastive in Tepehua. Although Proto-Totonac-Tepehua had a three-vowel inventory that excluded the mid vowels (Arana 1953; Brown et al. 2011), Huehuetla Tepehua currently has a five-vowel inventory in all areas of the lexicon, including native Tepehua words (e.g., ma:fte:wan 'brown tadpole', popa? 'man') as well as ideophones (e.g., se:nik 'sound of a tree falling', tt'o: 'jumping motion') and loanwords (e.g., te:nsu:n 'goat' from Nahuatl tentzontli 'goat', kone:hu: 'rabbit' from Spanish conejo). The phonemes /e(:)/ and $/ \mathrm{o}(:) /$ in many of the modern native Tepehua words were historically allophones of $/ \mathrm{i}(:) /$ and $/ \mathrm{u}(:) /$, whose lowering was conditioned by proximity

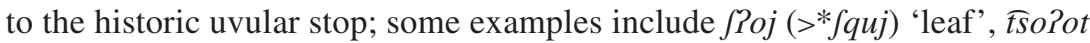

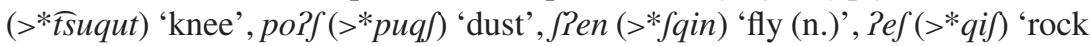
fence', si:le? (>*si:liq) 'cricket'. Minimal pairs that do not involve semantically related lexemes (such as pututu 'ball' and pototo 'really big ball') are hard to find, but they do exist (e.g., ?u:n 'wind' and Po:n 'fat'), evidence that Huehuetla Tepehua now has a five-vowel system.

Stress in Huehuetla Tepehua manifests in two ways: lengthening of the stressed vowel and increased intensity on the stressed syllable (Smythe 2000). Huehuetla Tepehua exhibits a highly unusual and complex stress assignment pattern in non-ideophonic and non-loan words, and we present only the briefest overview here in order to establish how the stress pattern for ideophones differs. In non-ideophonic native Huehuetla Tepehua lexemes, including nonideophonic adverbs, stress is assigned right to left. Primary stress falls on the final syllable of the word if it ends in the sonorant obstruent $/ \mathrm{n} /$ or a glide (h, ?, w, j) (1); otherwise it falls on the penult (2). Secondary stress is assigned to alternate syllables starting with the primary stress bearing syllable and moving from right to left (Kung 2007:105-6). Note, although $/ \mathrm{m} /$ and /1/ are also sonorant obstruents in Huehuetla Tepehua, separate phonological processes prevent these two phonemes from occurring in word-final position.

(1) Ultimate primary stress
a. p'ut.nan 'first'
b. Pa:li? 'more'
c. Tfa.waj 'now'
d. tfo:.lew 'multicolored'
e. ,tun.ka.hun 'daily'
f. 'la.,Pa.tfa.'Pan 'town' 
(2) Penultimate primary stress

$\begin{array}{ll}\text { a. 'Pak.sni: } & \text { 'when' } \\ \text { b. 'tu.Put } & \text { 'saliva' } \\ \text { c. la.'Pa.si: } & \text { 'first' } \\ \text { d. fna.pa.pa } & \text { 'white' } \\ \text { e. ma.:tu..pik } & \text { 'butterfly' } \\ \text { f. ,tf'a.Pa.waf.t'i } & \text { 'Totonac (person)' }\end{array}$

All examples in (1) demonstrate that stress falls on the final syllable when the word ends in the sonorant obstruent /n/ or a glide; (1e) and (1f) further show the alternate syllable placement of secondary stress. In (2), the examples show that when the word ends in any other sound, the penultimate syllable bears primary stress; (2f) demonstrates the secondary stress on alternate syllables.

Ideophones behave differently from other word types in that stress is assigned left to right, with primary stress always falling on the first syllable of the word and secondary stress on all subsequent syllables (Kung 2007:122 [147]); see (3).

(3) Stress in ideophones
a. '?u. $l i$
'delicious smell, smell of flowers'
b. '?u., li. li
'delicious smell'
c. $k a, n i$ 'delicious or beautiful odor'
d. ka. ni. ni 'delicious or beautiful odor'
e. 's?a., ha? 'bitter smell'

Examples (3a) and (3c) both bear primary stress on the penult and have a final syllable that ends in a short vowel. Whereas these words appear to follow the primary stress rule for non-ideophones, the examples in (3b), (3d), and (3e) do not follow the primary stress rule for non-ideophones since primary stress does not fall on the penult in (3b) or (3d) or on the final syllable ending in a glide in (3e). These ideophones also differ from non-ideophones in their assignment of secondary stress to every subsequent syllable from left to right. Since stress manifests as vowel-lengthening in Huehuetla Tepehua, this means that short vowels in ideophones do not sound short.

Ideophones differ phonologically from other native vocabulary in another way: while word-final short vowels are obligatorily devoiced or even optionally deleted in non-ideophones when they occur in isolation (Kung 2007:124-26), as seen in (4a) and (4b), respectively, they are always voiced and never deleted from ideophones in isolation (Kung 2007:437), shown in (4c) and (4d). ${ }^{2}$

\footnotetext{
2 Abbreviations: 1, first person; 3, third person; ART, article; DAT, dative; EMP, emphasis; FOC, focus; ID, ideophone; IMPFV, imperfective; INO, indefinite object; OBJ, object; IPOS, impersonal possessor; PF, perfect aspect; PFV, perfective aspect; PL, plural; POS, possessive; suB, subject; v, unspecified vowel quality in suffixes; voc, vocative. We use the following abbreviations for language names: FM Tot, Filomeno Mata Totonac; H Tep, Huehuetla Tepehua; Mi Tot, Misantla Totonac; Pa Tot, Papantla Totonac; PF Tep, Pisaflores Tepehua; Si Tot, Sierra Totonac; Tl Tep, Tlachichilco Tepehua; UN Tot, Upper Necaxa Totonac. We use IPA in the examples, some of
} 
(4) Short vowel devoicing and optional deletion in non-ideophones

a. Sa:-nati 'IPOS-mother'

b. Sa:-nat 'IPOS-mother'

No short vowel devoicing in ideophones

c. sk'uli 'a beautiful odor (floral or citrus)'

d. kififi 'hissing sound of a snake'

Word-final short vowels also weaken phrase-finally in non-ideophones, as in (5).

(5a) Phrase-final position, short vowel devoicing

hi: ki:nati

hi: ki:-nati

VOC 1 POS-mother

'Mother!'

(Kung 2007:125, ex. 105)

(5b) Phrase-internal position, no short vowel devoicing

hu: nati $\int$ ?o:j

ART mother dog

'female dog'

(Kung 2007:125, ex.106b)

In (5a), ki:nati 'my mother' occurs at the end of the vocative phrase, and the word-final short vowel is devoiced. Compare this with (5b) in which nati occurs phrase-internally, and the word-final short vowel is voiced.

Ideophones in Huehuetla Tepehua belong to the adverbial word class; specifically, they are a type of manner adverb. Like all adverbs in this language, ideophones precede the verbs they modify, and they are never inflected. By virtue of their status as adverbs, ideophones never occur in a phrase-final position, which is the very position in which non-ideophonic lexemes undergo the process of final-short vowel devoicing described above. However, ideophones frequently occur in isolation-for example, during elicitation or in response to a question. Such examples are seen in (6), where the word-final short vowels are not devoiced phrase-finally.

(6a) wa: me?e

FOC ID

'It smells of beef cooking.'

(Kung and O'Meara 2014:36)

which have been adapted from examples provided in practical orthographies in other TotonacTepehua languages. 
(6b) na: kanini

EMP ID

'It smells good, savory.'

(Kung and O'Meara 2014:50)

Ideophones, like other manner adverbs, may be repeated; however, ideophones differ in that they are the only class of words in Huehuetla Tepehua that undergo reduplication, the semantics of which are discussed in more detail in 2.3. Non-ideophonic adverbial words and phrases may be repeated for emphasis (Kung 2007:437-38), as seen in (7).

Reduplication in non-ideophones

(7a) Tfawaj trawaj k'ananta ţawaj ţawaj k-?an-an-ta now now 1suB-go-?-PF

'I'm going now, now.'

(7b) na: $\operatorname{lo}$ na: $\operatorname{lo} \int \mathrm{ki} f k a n i j$ [na: $\left.30 \int\right] \quad\left[\right.$ na: $\quad$ ?of] kin- $\int k a-n i-j$ EMP good EMP good 1OBJ-hurt-DAT-IMPFV

'I hurt very, very badly.'

(Kung 2007:438)

Both repetition and reduplication are especially salient in Huehuetla Tepehua ideophones, which undergo not only the complete repetition seen above in (7) but also partial and iterative reduplication as well. Complete repetition in ideophones can be linked to the number of times a discrete action or event takes place. An ideophone pronounced one time without repetition can mean the sound, action, or sensation being referred to occurred once, as in (8a), but if the word is repeated, then multiplicity is indicated, as in (8b).

(8a) la?a makat'awł hu: kimpi:ftu?

la?a makat'ahun-li hu: kin-pi:ftu?

ID sound-PFV ART 1POS-neck

'My neck popped once.'

(8b) la?a la?a makat'awł hu: kimpi:ftu?

la?a la?a makat'ahun-li hu: kin-pi:ftu?

ID ID sound-PFV ART 1POS-neck

'My neck popped several times.'

[la?a 'popping noise']

(Kung 2007:439)

In reduplication, the final syllable may be reduplicated to indicate the sound, action or sensation is long, continuous, or enduring. The examples in (9) show 
what Kung (2007) calls partial reduplication (9b) and iterative reduplication (9c).

(9a) kani 'delicious or beautiful odor'

(9b) kanini 'strong or enduring delicious or beautiful odor'

(9c) kaninini 'especially strong or enduring delicious or beautiful odor'

In (9b) and (9c), iterative reduplications of the final syllable are used iconically to indicate an even longer-lasting or enduring sound, action, or sensation (Dingemanse et al. 2015).

Huehuetla Tepehua has several morphological frames that allow a verb stem to be derived from an ideophone. One such frame is illustrated in (10) with the olfactory ideophone $p^{\prime} u k s$, which is used to describe strong, stinky odors.

(10a) p'uks p'uks ?akamin hu: ti:waj

p'uks p'uks ?akamin hu: li:waj

ID ID smell ART meat

'The meat stinks.'

[p'uks 'a strong and stinky odor' (e.g., smell of rotten meat)]

(10b) Rap'uksnun hu: makftał

?a-p'uks-nVn hu: makftał

PL.INO-ID-INO:IMPFV ART garbage

'The garbage stinks.'

(Kung 2007:443)

In (10a) the repeated ideophone modifies the verb Pakamin, the general "smell" verb. However, in (10b) the ideophone is affixed with the indefinite object prefix and suffix, which results in the derivation of an intransitive verb stem whose meaning is based on that of the ideophone. In five morphological frames, an ideophone can serve as the root of a derived verb (see Kung 2007:441-46).

Finally, Huehuetla Tepehua ideophones are subject to a process of systematic sound-symbolic phonemic alternations in which a templatic alternation between phonemes results in a slight change in meaning. Pairs of related ideophones, adapted from Kung (2005:13, ex. 26), are shown in (11).

(11a) kakf 'sound of a branch breaking'

kaks 'sound of a twig snapping'

(11b) p'ititi 'sound of light rain, sprinkling'

$p$ 'isisi 'sound of even lighter rain, sprinkling'

(11c) $\widehat{t} \rho$ ' $e$ ' 'sound of a bird, chirp, tweet'

ts'ik 'sound of a mouse, squeak'

Phoneme alternations include palato-alveolar fronting/backing $\left[\int \sim \mathrm{s}\right](11 \mathrm{a})$, alveolar (de)lateralization $[\mathrm{t} \sim \mathrm{s}](11 \mathrm{~b})$, and mid-vowel raising/lowering [e $\sim \mathrm{i}]$ 
TABLE 3

Huehuetla Tepehua Phonemic Alternations

Diminutive;

Affectionate Speech Augmentative

consonant fronting consonant backing

s $\quad 5$

s 1

ts, ts' $\widehat{\mathrm{t} f}, \widehat{\mathrm{ts}}$

k, k' $\quad$, *q, *q'

vowel raising vowel lowering

i, u e, o

(11c) (see also table 3). These systematic sound-symbolic phonemic alternations are not limited to the class of ideophones; rather they occur in all word classes of the language and play a role in four other areas of the lexicon: diminutive/augmentative, affectionate speech register, lexical sets, and phonemic alternations in body-part prefixes (Kung 2007:146-47).

The parts of the lexicon in which sound-symbolic phonemic alternations play a role are similar to what Klamer (2002) has described as the different classes of items that involve expressive semantics. In Huehuetla Tepehua, three different consonant sets and one vowel set play a critical sound-symbolic role in form-to-meaning mappings. Table 3 shows that consonant fronting and vowel raising are linked to a diminutive meaning and affectionate speech register, whereas consonant backing and vowel lowering are linked to augmentative interpretations. Similar associations have been reported in other languages (e.g., Sapir 1911 for Wishram; Nichols 1971 for Western North American languages; Ultan 1978; Haynie et al. 2014 for Australian languages).

Examples of the diminutive/augmentative contrast are given in (12); bold font is used to indicate the alternating phonemes.

Diminutive/augmentative contrast in non-ideophones

(12a) to?o?o 'hollow thing'

sukuku 'small, hollow thing'

(12b) tputut 'round thing'

sputut 'small, round thing'

potot 'large, round thing'

(12c) kit 'mouth'

Pet 'big mouth'

(Kung 2007:148)

In $(12 \mathrm{a})$ the alternations are $[1 \sim \mathrm{s}],[\mathrm{o} \sim \mathrm{u}]$ and $[\mathrm{p} \sim \mathrm{k}]$; in $(12 \mathrm{~b})[\mathrm{f} \sim \mathrm{s}]$, $[\mathrm{o} \sim \mathrm{u}]$; and in $(12 \mathrm{c})[\mathrm{P} \sim \mathrm{k}]$ and $[\mathrm{i} \sim \mathrm{e}]$. These examples demonstrate that the phonemic alternations shown in table 3 are productive, in that they are commonly used and may be applied to any word; however, some alternating pairs 
have become lexicalized, as in (13). The semantic characteristics described for productive phonemic alternations are not necessarily transparent in such lexicalized pairs.

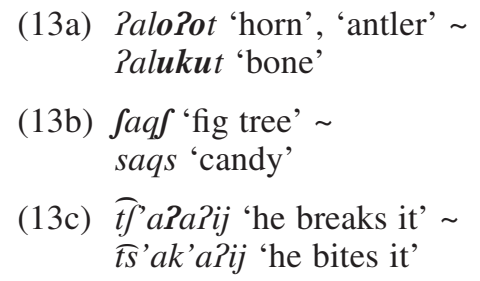

(Kung 2007:153-55)

Prior to the field trip described below, our preliminary search of Kung's Huehuetla Tepehua lexical database (described in 2.2) produced only six smell terms, all of which patterned like ideophones, so we hoped to elicit further odor terms through targeted elicitation. We did not, however, expect to find previously unattested sound-symbolic phonemic alternations in the data; in fact, we found two patterns of phonemic alternations that neither Kung $(2005,2006 a, 2006 b, 2007)$ nor Herzog (1987) had previously described for this language.

In the first pattern, the low vowel /a/ participates in sound-symbolic alternations, as seen in (14). Note that the forms in (b) are reduplicated forms of those in (a).

(14a) tkak 'spicy odor and taste' tkuk 'odor of lime (calcium hydroxide, cal)'

(14b) tkakak 'odor or flavor so spicy/strong that it will make one sneeze' tkukuk 'odor of peppermint'

(14c) siah 'rancid, sour odor' s?eh 'delicious odor'

In (14a) and (14b), /a/ alternates with /u/, resulting in a subtle meaning change; in (14c), /a/ alternates with /e/, producing a drastic change. Both patterns conform to the pattern of vowel raising and lowering shown in table 3 . It appears that these types of phonemic alternations are akin to what Tufvesson (2011) has described for sensory perception ideophones in Semai-that is, systematic vowel alternations lead to meaning change in formally similar words.

In the second previously undescribed alternation, the alveolar fricative /s/ alternates with the alveolar affricate / $\widehat{\mathrm{ts}}$ '/, shown in (15), where there is only a slight change in meaning.

(15) saw 'very disagreeable odor (e.g., dead animal, smelly dog)' ts' $a w$ 'smell of excrement, odor stronger than saw' 
This pattern of (de-)affricatization is unlike any that has previously been described for this language. It is unusual for a glottalized affricate to alternate with a fricative in this language family, and we have no explanation for this anomaly. The two words in this alternating pair were produced by different speakers at different times, and the formal and semantic similarities were uncovered later when we analyzed the data. Because both form and meaning are so similar, we include this example.

Though these two patterns have not been described previously, on revisiting the matter we found more ideophonic examples in Kung's lexical database. Additional examples of vowel lowering/raising that involve the low vowel /a/ are shown in (16). The process of vowel lowering and raising is readily applied to the high and mid vowels; however, in these examples the process has extended to include the low vowel /a/ as well.

(16a) $/ \mathrm{e} / \sim / \mathrm{a} /$ slewak 'action of cutting something into strips with a machete' slawa? 'action of slipping on a wet surface'

(16b) $/ \mathrm{u} / \sim / \mathrm{a} /$ slum 'the way a lizard looks when it moves (its legs move so fast it looks like it is gliding)' slam 'the way a flashing light looks'

(16c) $/ \mathrm{u} / \sim / \mathrm{a} /$

tkuluk 'action/sound of walking with a limp' tkalak 'action/sound of galloping or running'

(16d) $/ \mathrm{u} / \sim / \mathrm{a} /$

tkululu 'the way lice move'

tkalala 'the way a critter with pincers moves with its pincers opened'

Though no other examples of the (de-)affricatization involving the glottalized / $\widehat{\text { ts}}$ / were found, we did find examples in which /s/ alternates with the plain / $\mathrm{ts} /$, as in (17).

(17a) sam 'sound of a small pop or splash' tsam 'sound of biting into something tender'

(17b) sas 'sound of glasses clinking (e.g., a toast)' tsas 'a loud shout'

To summarize, ideophones in Huehuetla Tepehua show a number of characteristics that in combination distinguish them from other word classes in the language. Syntactically and morphologically they pattern with manner adverbs. Phonemic alternation and reduplication allow for new word forms to describe sensory experiences (and motion events; not in focus here). It can be difficult to determine the underlying roots of ideophones because there is 
much variation in patterns of reduplication and sound-symbolic alternations. The individualized, ideolectal nature of this class of words means they are ideal for conveying personal, particular sensory experiences in a cogent manner. At the same time, there are regular form-to-meaning mappings expressing size (augmentative/diminutive) and speech register (affective speech). Since smell terminology is so little explored, it behooves us to look more closely at how these processes operate in the olfactory domain.

2.2. Eliciting odor terms in Huehuetla Tepehua. Tepehua has been documented in-depth by Kung, so we began by searching for odor terms in her Huehuetla Tepehua lexical database. Kung started an unpublished Toolbox database (filename tpwlex.db) in Shoebox in 1999. She added to this database continuously from 1999 through 2008, and again for the month of November 2011. This database was static from December 2011 until August 2014 when the fieldwork reported here was carried out and was only modified as a result of this fieldtrip. It consists of some 6,150 lexemes which stem from translation elicitation, including ideophone-specific elicitation that targeted the visual and auditory domains, as well as conversation and natural monologue texts. The database includes 528 ideophones, of which 213 were ideophones of sounds, 124 of actions, 104 of vocalizations (including animal calls, cries, songs, ways to call animals), and 21 for sensations. However, prior to the study carried out in August 2014 and described here, only six were specific to olfaction. From this, one could conclude that olfaction is not very salient to this community and leave it at that. However, given the previous reports of olfactory terminology in these languages (Aschmann 1946; Santiago Francisco 2009; Enríquez Andrade 2010; McFarland 2010), as well as the fact that we found some olfactory ideophones in Huehuetla Tepehua, this conclusion seemed premature. ${ }^{3}$ So we turned to a different method to elicit potential odor vocabulary.

We presented 20 native speakers of Huehuetla Tepehua with 18 different odors, using Sniffin' Sticks (Hummel et al. 1997). These are marker pens containing an odorant instead of ink. Participants smell the odor by removing the marker cap and sniffing the tip of the pen. The Sniffin' Sticks contained

\footnotetext{
${ }^{3}$ In earlier research, Kung elicited ideophones with two different speakers by taking everyday objects and using them to make sounds (e.g., shaking a box of paperclips, popping rubber bands, tapping pencils on the table) and enacting different manners of motion (e.g., hopping on one foot, limping, walking with big steps). One speaker spontaneously started providing terms to describe how people, animals, fish, and other things in nature move. Interspersed with these terms were ideophones that describe the way light or water plays on various surfaces. The terms collected with these two speakers were checked with a third speaker and were approved. During this type of elicitation, speakers did not spontaneously produce any ideophones for smell or taste. The few olfactory terms collected come from translation elicitation and one was produced in an oral history narrative.
} 
odors that correspond to the following "odor objects": apple, banana, clove, eucalyptus, garlic, lavender, leather, lemon, lilac, mushroom, pineapple, peppermint, rose, sesame, smoked meat, soy sauce, turpentine, and vinegar. The sticks were presented one at a time in a fixed random order. We waited at least 30 seconds between presenting speakers with different odors to avoid olfactory fatigue. Participants smelled each stick for as long as they wanted. They were then asked in Tepehua "How does it smell?" (Taas Pakamin?). We recorded the responses with an audio-recorder and with pencil and paper. Before working with speakers, they were informed about the protocol, and consent was obtained. Upon completing the task, we debriefed speakers regarding the experiment and asked if they could think of any other smells not included in the task. We also asked follow-up questions regarding terms not previously documented.

Working with real odorants in the form of Sniffin' Sticks was successful in eliciting a rich set of olfactory terms not previously attested, many of which show ideophonic properties. This is noteworthy since the database of ideophones was of considerable size with 528 terms overall. After this elicitation study, the database went from having merely 6 olfactory terms-all ideophones-to 45 total forms, including ideophones. This suggests that the current cross-linguistic paucity of documented olfactory language cannot be trusted.

Of the terms that were elicited, some refer to tastes as well as odors. This likely reflects the physiological conflation of these senses. Chemosensory researchers distinguish between "taste" proper (i.e., sweet, sour, bitter, salty, umami) and "flavor," which combines taste and texture with olfaction to produce the sensation we experience in the mouth (Smith 2012). The olfactory system is triggered both by sniffing ("orthonasal olfaction") and when an object enters the mouth: molecules travel to the olfactory system through the back of the oral cavity ("retronasal olfaction"). It is, therefore, perhaps expected to see a close connection between these senses (Shepherd 2006). For our purposes, the distinction between taste and flavor is not crucial and, as such, we will use the generic term "taste" to refer to the sensory experience in the mouth.

In response to the odor naming task, speakers used olfactory terms $59 \%$ of the time (see table 4). ${ }^{4}$ On the other hand, $36 \%$ of responses to the task involved a source-based term or expression to say that a Sniffin' Stick smelled like VapoRub, for instance. Only one participant gave an evaluative response, indicating that a Sniffin' Stick smelled "nice." In the first part of the protocol, speakers simply named the odor or its source in response to smelling each

\footnotetext{
${ }^{4}$ To consult audio recordings of the words listed in table 4, see the following record in AILLA, https://www.ailla.utexas.org/islandora/object/ailla\%3A255668, which may be freely accessed and used according to AILLA's user guidelines (https://www.ailla.utexas.org/).
} 
TABLE 4

Huehuetla Tepehua Olfactory Terms

\begin{tabular}{|c|c|c|}
\hline $\begin{array}{l}\text { Ideophonic } \\
\text { Group }\end{array}$ & Odor Term & Description \\
\hline \multirow[t]{5}{*}{1} & Puli & Delicious smell, smell of flowers \\
\hline & Pulili & Delicious smell \\
\hline & k’uli & A beautiful, rich odor like perfume or flowers \\
\hline & k’ulik & A rich, beautiful odor like lavender \\
\hline & sk'uli & A beautiful odor (floral or citrus) \\
\hline 2 & tfaktfi & $\begin{array}{l}\text { UNDETERMINED MEANING; elicited as a response to Sniffin' Stick } \\
\text { pineapple odor }\end{array}$ \\
\hline 3 & ţaja:w & Flavor and/or scent of flavored water \\
\hline 4 & $\mathrm{t} \mathrm{i}: \int$ & $\begin{array}{l}\text { Smell of urine or excrement (human or animal), or of a person } \\
\text { who does not bathe }\end{array}$ \\
\hline 5 & hak $\int$ & Smell and flavor of guaxi ${ }^{1}$ \\
\hline \multirow[t]{3}{*}{6} & kan & $\begin{array}{l}\text { Delicious odor of free range chicken that eats corn instead of } \\
\text { chicken feed; (also fruity odors) }\end{array}$ \\
\hline & kani & A delicious odor; a beautiful odor \\
\hline & kanini & Elicited as a response to Sniffin' Stick clove odor \\
\hline 7 & $k^{\prime} u s^{2}$ & A beautiful odor \\
\hline 8 & li:tsi & A really bad odor \\
\hline \multirow[t]{6}{*}{9} & tkak & Spicy odor and taste \\
\hline & łkakak & Odor or flavor so spicy/strong that it will make one sneeze \\
\hline & tkakaka & Elicited as a response to Sniffin’ Stick eucalyptus odor \\
\hline & łqaqa 13a?a & Spicy odor or flavor, but not as strong as lhkak \\
\hline & tkuk & Odor of lime (calcium hydroxide) \\
\hline & tkukuk & Odor of peppermint \\
\hline \multirow[t]{5}{*}{10} & tkih & $\begin{array}{l}\text { Delicious, savory odor like when shrimp or mushrooms are } \\
\text { boiling, the smell of coffee, recently wet earth }\end{array}$ \\
\hline & tkeh & Odor even more delicious than $t k i h$ \\
\hline & tk'ih tk'ihni & Delicious odor of food, pleasant odor like incense, flowers \\
\hline & s?eh & $\begin{array}{l}\text { Delicious odor (e.g., of honey or sugar cooking), richly cooked } \\
\text { food, frying meat, beans, pork skins, ripe avocado }\end{array}$ \\
\hline & $\int$ Peh & $\begin{array}{l}\text { Unpleasant smell like skunk, human farts, burning plastic, hair, } \\
\text { feathers, horns, bones, chile or cloth, tobacco, garbage }\end{array}$ \\
\hline 11 & ma: $\int$ & $\begin{array}{l}\text { Something that has gone bad, similar to } p^{\prime} u k s \text {, but not as bad of } \\
\text { an odor }\end{array}$ \\
\hline 12 & me?e $\sim$ meqe & $\begin{array}{l}\text { Smell of raw milk, raw beef, sheep's meat, or beef when it's } \\
\text { cooking }\end{array}$ \\
\hline 13 & mi:s & $\begin{array}{l}\text { Smell of a particular herb, women's makeup or perfume, smell } \\
\text { of badger }\end{array}$ \\
\hline \multirow[t]{2}{*}{14} & mo?o? & $\begin{array}{l}\text { Smell of something that has gone bad, it makes you nauseous, } \\
\text { the taste of something that is off, not flavorful, or lacks salt }\end{array}$ \\
\hline & mukuk & Pleasant odor, perfume, flowers, a clean person \\
\hline \multirow[t]{3}{*}{15} & p'orf & $\begin{array}{l}\text { Mildew odor, damp clothes that didn't dry well, rotten fruit, wet } \\
\text { towel, wet dog }\end{array}$ \\
\hline & p'uks & A terrible smell like dirty diaper, rotten meat, dead animal \\
\hline & p'ukf & Smell of rotten wood \\
\hline
\end{tabular}




\begin{tabular}{|c|c|c|}
\hline 16 & s?ah & $\begin{array}{l}\text { Rancid, sour odor (e.g., of a person that does not bathe, rotten } \\
\text { citrus fruit) }\end{array}$ \\
\hline & s?aha? & $\begin{array}{l}\text { A bitter smell, like zest from the skin of citrus fruit, the smell of } \\
\text { lemons }\end{array}$ \\
\hline & skah & A sour odor, like sweat or fermentation \\
\hline 17 & s?o?o & Salty taste and odor \\
\hline 18 & sa?si & $\begin{array}{l}\text { Sweet odor and taste, like fruit (was used to describe various } \\
\text { Sniffin' Sticks) }\end{array}$ \\
\hline & takł(i) & Bittersweet odor and taste of a ripe fruit \\
\hline 19 & saw & $\begin{array}{l}\text { A very disagreeable odor, so stinky it is unbearable (e.g., of an } \\
\text { animal or person dead for several days), extremely smelly dog }\end{array}$ \\
\hline & ts'aw & Smell of excrement, stronger odor than saw \\
\hline 20 & skakak & $\begin{array}{l}\text { Strong odor that takes three days to disappear (e.g., smell of } \\
\text { skunk, gas, a green cockroach) }\end{array}$ \\
\hline 21 & su:n & A bitter (savory) odor \\
\hline & fu:n & A bitter odor, smell of burnt food \\
\hline 22 & ta: & $\begin{array}{l}\text { UNDETERMINED MEANING; elicited as a response to Sniffin' Stick } \\
\text { vinegar, soy sauce and rose odors }\end{array}$ \\
\hline 23 & t'ol & Sharp odor, chalky or pasty odor \\
\hline & t’uł & $\begin{array}{l}\text { A disgusting odor like animal urine or excrement, cold and raw } \\
\text { egg, raw meat of an animal that eats feed instead of corn }\end{array}$ \\
\hline
\end{tabular}

\footnotetext{
${ }^{1}$ Guaxi is an edible pod, likely from a tree in the Leucaena genus.

${ }^{2}$ An anonymous reviewer accurately pointed out that k'us 'beautiful, pretty' is the diminutive form of the historical Huehuetla Tepehua * $q$ 'of(i) (modern form ?of) 'good'. However, in Huehuetla Tepehua $k$ 'us has lexicalized to the point that Huehuetla Tepehua speakers do not immediately recognize it as the diminutive of $20 f$.
}

Sniffin' Stick; they were not asked any follow-up questions at this time. However, in the debriefing part of the protocol, speakers would name odors and describe them, sometimes guessing at the possible sources too, as shown in (18) wherein the speaker was guessing that a sweaty child could be the source of the odor named by s?ah, which directly precedes Pakamin, the general smell verb 'smell, give off an odor'.

(18) na: wa: s?ah Pakamin hu: STas?at'a

$\begin{array}{llllll}\text { na: } & \text { wa: } & \text { s?ah } & \text { Pakamin } & \text { hu: } & \int \text {-Pas?at'a } \\ \text { very } & \text { FOC } & \text { ID } & \text { smell } & \text { ART } & \text { 3POS-child }\end{array}$

'The child smells very sour (e.g., from sweat).'

[s?ah 'sour, sweaty smell']

(Kung and O’Meara 2014:8)

Table 4 provides all olfactory terms elicited by the Sniffin' Sticks and follow-up interviews. The semantic characterization of each term in table 4 is gleaned from information obtained from consultants in the follow-up interviews. Shading, or lack thereof, in the table illustrates groups of terms (in no particular order) that are related by patterns of sound-symbolic phonemic alternation or reduplication. In general, these odor terms undergo the same 
processes of reduplication and phonemic alternations previously described for ideophones (Kung 2005, 2006a, 2006b, 2007; see 2.1). In some cases, a single lexeme is listed for a group; it is quite plausible that related terms have yet to be documented.

It has been claimed that ideophones express highly specific meanings (e.g., Dingemanse 2011:228). Semantically specific words can be defined as words with more "bits of information" or "components of meaning," and correspondingly they have smaller extensions (Lyons 1968:454) because their larger number of meaning components means their reference is more restricted. The odor terms in table 4 appear to be semantically specific in this sense, since utterances with these terms have a limited extension relative to utterances with the general smell verb 'akamin 'smell, give off an odor'. Although these terms are semantically specific, they do not refer to a particular odor source, which is similar to what has been described for olfactory predicates in the Aslian languages (Majid and Burenhult 2014; Wnuk and Majid 2014).

Finally, previous studies of ideophone-rich languages have described ideophones as being challenging to elicit (e.g., Samarin 1967; Mithun 1982; Blench 2010). Although we may not have elicited an exhaustive list of odor vocabulary in Huehuetla Tepehua, using odor stimuli as an elicitation tool, we obtained a large corpus of odor terms that had previously been undocumented. However, although the procedure used here was helpful in eliciting terms, it did not provide a complete picture for understanding the semantics of the terms it generated. To supplement, we conducted follow-up elicitation after the Sniffin' Sticks task using both free-listing and general elicitation, which gave us further insight into meaning distinctions of the terms used. We acknowledge the limitations of our current data, but combining these different methods of elicitation provided a more complete picture than using only one, or none at all, and provides a firm foundation for further investigation.

2.3. Form-to-meaning mapping in Huehuetla Tepehua odor terms. Phonemic alternations in Huehuetla Tepehua words can be interpreted in different ways depending on the specific lexical field under consideration. In the context of ideophones that refer to sensorial experiences, phonemic alternations can indicate a change in some aspect of the percept, including a change in the perceived intensity. A generalization emerges among perception ideophones whereby the same sounds associated with the augmentative (consonant backing and vowel lowering) shown in table 3 can be interpreted to indicate a more intense sensation; sounds associated with the diminutive (consonant fronting and vowel raising), in contrast, can be interpreted as less intense. This is seen in (19) and (20), wherein consonant backing and vowel lowering, respectively, are linked to more intense perceptual experiences in the olfactory domain. 


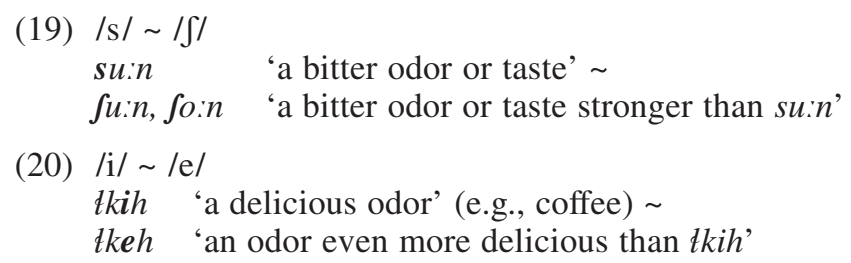

However, although most odor terms align with this generalization, counterexamples are available, as in (21), where consonant backing is linked to a less intense perceptual experience, and (22), where it is impossible (for cultural outsiders) to determine if one smell is more intense than the other.

(21) $/ \mathrm{k} / \sim / \mathrm{q} /$

lkak 'a spicy odor or taste'

tqaqa, tqaq 'a spicy odor or flavor, but not as strong as $t k a k$ '

(22) $/ \mathrm{k} / \sim / \mathrm{R} /$

skah 'a sour odor, like sweat or fermentation'

s?ah 'rancid, sour odor, like a person who does not bathe or rotten citrus fruit'

Nevertheless, it is unequivocally the case that sound-symbolic alternations in odor terms produce changes in meaning, as seen in the previous examples, and in (23).

(23) $/ \mathrm{u} / \sim / \mathrm{o} /, / \mathrm{k} / \sim / \mathrm{P} /, / \mathrm{s} / \sim / \mathrm{S} /$

p'o?f 'odor of mildew, damp clothing, wet dog, rotten fruit'

p'uks 'terrible smell like dirty diaper, rotten meat, dead animal' p'ukf 'smell of rotten wood'

Furthermore, we observed some phonemic alternations that lexicalize differing hedonic values or pleasantness between contrasting pairs, as in (24) and (25). In (24) there is both vowel lowering and consonant backing, whereas in (25) we see only consonant backing.

(24) $/ \mathrm{u} / \sim / \mathrm{o} /$ and $/ \mathrm{k} / \sim / \mathrm{R} /$

mukuku 'a pleasant odor' (e.g., perfume)

moPo?o 'an unpleasant odor' (e.g., spoiled food)

(25) $/ \mathrm{s} / \sim / \mathrm{s} /$

s?eh 'a delicious odor' (e.g., rich food being cooked)

fieh 'a really bad odor' (e.g., hair, bone, etc., burning)

Contrasts in hedonic values in ideophones have been observed in other languages, specifically in Ewe, a Kwa language of West Africa, where it is marked by a tonal contrast: lílílílíli 'nice good sweet smell' (high tone) vs. lìlìlilì 'very bad smell' (Ameka 2001:30). 
TABLE 5

Hedonic Value Shifts in Huehuetla Tepehua

Expressed by Phonemic Alternations

\begin{tabular}{cc}
\hline \hline Pleasant & Unpleasant \\
\hline consonant fronting & consonant backing \\
$\mathrm{s}$ & $\int$ \\
$\mathrm{s}$ & 1 \\
$\mathrm{k}$ & $\mathrm{2},{ }^{*} \mathrm{q}$ \\
vowel raising & vowel lowering \\
$\mathrm{u}$ & $\mathrm{o}$ \\
\hline
\end{tabular}

In these Tepehua data, we also observed phonemic alternations that lexicalize only slight differences in hedonic values, such as the contrast pair found in (26).

(26) $/ \mathrm{s} / \sim / \mathrm{t} /$ and $/ \mathrm{k} / \sim / \mathrm{l} /$

sa?si 'a sweet smell or taste'

takti 'a bittersweet smell or taste'

Yet another pattern emerges from many of the lexical sets: consonant fronting and vowel raising are generally linked to pleasant smells and consonant backing and vowel lowering are linked to unpleasant smells, summarized in table 5. In comparing multiple West African languages, Westermann $(1927: 328 ; 1937: 209-10)$ noted a very similar pattern in high vowels and "hard" consonants mapping onto meanings of pleasant smells and spicy intense tastes, whereas low, deep vowels and "soft" consonants map onto meanings of repulsive smells and insipid tastes.

In some theories of olfaction, odors are primarily perceived according to their pleasantness (e.g., Khan et al. 2007; Yeshurun and Sobel 2010), and there appears to be a direct link between the molecular structure of an odorant and its perceived pleasantness (Keller et al. 2017). The Huehuetla Tepehua data seem perplexing in this context. If an olfactory lexeme is picking out a specific odor quality, it is not clear how a "sound-symbolic" phonemic alternation can signal a completely different odor quality. We suggest the bridging context (Wilkins 1981) contributing to the interpretation of pleasant odor qualities could be through the affectionate speech register. Phonemic alternations that indicate affection come to specifically indicate positive odor, and the oppositional contrast leads to an interpretation of negative odor. Although plausible, this account still leaves some puzzles. It is not clear how the specific formal contrast leads to the specific positive or negative odor-quality meaning. For example, in (25) the phonemic alternation from $s ? e h$ to $\int ? e h$ changes the meaning from 'a delicious 
odor (e.g., rich food being cooked)' to 'a really bad odor (e.g., hair, bone, etc., burning)'. We might expect the contrast to be more transparent between a pleasant and an unpleasant odor, but we find a more specific and idiosyncratic meaning opposition. Similarly, $p$ 'uks 'a terrible smell like dirty diaper, rotten meat' contrasts with $p$ ' $u k f$ 'smell of rotten wood'; $t$ 'ot 'a sharp odor' contrasts with $t^{\prime} u t$ 'a disgusting odor'. The specific interpretation is not always transparent. The question then becomes to what extent these alternations are arbitrary-a matter of language- and culture-specific interpretation-or sound-symbolic, such that they reveal how forms map onto the olfactory system capturing universal notions of contrast. The data are simply not sufficient to adjudicate the matter at present; however, this would be a promising avenue to explore in the future since it would shed new light onto sound-symbolism and olfaction.

During the Sniffin' Sticks protocol and follow-up elicitation, we also observed two patterns of reduplication that were previously described by Kung (2005, 2006a, 2006b, 2007)—specifically, the patterns of partial reduplication, wherein the final syllable undergoes reduplication (27a), and iterative reduplication, wherein the final syllable is reduplicated iteratively (27b).

(27a) taţ hu: mi:si: k’ulili Pakamin tat $\int$ hu: mi:si: k'uli ?akamin like ART pápalo ID smell 'It smells good like pápalo (an herb, Porophyllum coloratum).' [ $k$ 'uli 'good smell like a flower or perfume']

(Kung and O'Meara 2014:14)

(27b) wa: kaninini Pakamin na: ?ala:fu: $\int$

wa: kani ?akamin na: Pala: $\int u: \int$

FOC ID smell ART orange

'It smells really delicious, really orangey.'

[kani 'delicious smell']

(Kung and O'Meara 2014:45)

Similarly, while reduplication, in general, can have an iterative meaning, in the sensorial domain it can be interpreted as an intensifier. So the reduplicated form in (28) indicates a more intense odor or taste than the unreduplicated form.

(28) tkak 'spicy odor or taste'

tkakak 'even more spicy odor or taste than $t k a k$ '

Interestingly, repetition of the ideophone did not emerge during the Sniffin' Sticks protocol or follow-up questions, nor did we specifically try to elicit it. This might be explained by the fact that total repetition is associated with 
iterativity in punctual events, which would not apply to odors since they behave more like states. ${ }^{5}$

To summarize the general phonemic alternations in odor terms, we see that they are formally the same as the alternations found in other sensory domains. Reduplication is linked to subtle changes in the percept, particularly intensification of the sensorial experience. Although phonemic alternations in ideophones are the same as those found in other arenas (i.e., affectionate speech, diminutive/augmentative), the changes in meaning appear more complex.

There are a final few remarks to be made about the semantics of odor terms in Tepehua. In his formative study, Aschmann (1946) grouped odor terms in Totonac formally on the basis of their shared basic smell roots, and he provided a semantic label for each group. For instance, odor terms beginning with pu were grouped as 'bad smells' (see 3.2). There were also 'vegetation and good smells', 'medicinal and aromatic smells', 'body and animal smells', 'sour smells', and 'smells that leave a taste in the mouth'. In table 4, we also attempted to draw on the formal similarity of odor terms in Tepehua, but we found a "smell root" does not necessarily have a common meaning component, especially when a phonemic alternation changes the hedonic value of the term (see examples 24 and 25). In such cases, it is not clear what the common meaning of the "smell root" would be, were an abstract form to be proposed. This also points to the fact that there is no direct relationship between the term's form and the odor quality expressed by that term.

Nevertheless, some generalizations emerge if we consider all lexemes; certain categories of odors appear salient: fecal and/or rotten odors (e.g., saw 'stinky odor', $\widehat{t} s$ ' aw 'smell of excrement', $t$ 'ut 'disgusting odor', $\widehat{t} f i: \int^{\prime}$ 'smell of excrement or urine', $p$ 'o?f 'mildew odor', $p$ 'uks 'terrible odor', $p$ ' $u k f$ 'smell of rotten wood', ma:f 'smell of something gone bad', mo?o? 'smell of something that has gone bad', siah 'rancid or sour odor'), aromatic or perfume-like odors (e.g., Puli 'delicious odor', Pulili 'delicious odor', $k$ 'uli 'beautiful odor like perfume', k'ulik 'beautiful odor like lavender', sk'uli 'beautiful odor', $k$ 'us 'beautiful odor', mi:s 'smell of an herb, badger, etc.', $t k$ 'ih 'delicious odor'), edibility and deliciousness (e.g., sa?si 'sweet odor', takt(i) 'bittersweet odor', $s ? e h$ 'delicious odor', tkih 'delicious, savory odor', $t k e h$ 'very delicious odor', $t k$ 'ih 'delicious odor', hakf 'smell of an edible pod', ț'aja:w 'smell of flavoured water', me?e 'smell of raw milk, etc.') and finally inedibility (e.g., s?ah 'rancid, sour odor', skah 'sour odor', fu:n 'bitter odor', ma:f 'smell of something that has gone bad', t'ut 'disgusting odor'), which contrasts with the edible set of terms. The proposed categories differ from the ones that Aschmann (1946) identified, but both require further grounding in data from speakers. Finally,

\footnotetext{
${ }^{5}$ We thank David Beck for suggesting the possible explanation for why total repetition did not occur in this context.
} 
ideophones have been characterized as being depictive of specific sensory imagery (Dingemanse 2012). This seems intuitive in the case of sound and motion ideophones, which can invite interlocutors to imagine a particular sound or motion illustrated by an ideophone using either imagic iconicity in which a form depicts a sound or relative iconicity in which different levels of intensity are mapped onto vowel space (Dingemanse 2012:663). It is less clear how speakers invite interlocutors to imagine a particular smell based on the way an ideophone sounds. In addition, sound-symbolic phonemic alternations provide information about odor pleasantness but do not indicate odor quality. Further work is necessary to disentangle the systematic sound-symbolic nature of olfactory ideophones from the "roots" or "templates" that provide further lexical content regarding odor quality.

3. Olfactory lexicon in other Totonac-Tepehua languages. The quantity and quality of odor terms in Huehuetla Tepehua is not something unique to this language, as we indicated in the introduction (1). In fact, all Totonac-Tepehua languages have numerous odor terms that make significant use of phonemic alternations, and many of the languages are documented as being rich in ideophones. This has been illustrated for both branches of the language family: Totonac (McQuown 1990 [1940]; Aschmann 1946; Bishop 1984; Levy 1987, 2004; Enríquez Andrade 2004, 2010; Beck 2007, 2008; Santiago Francisco 2009; McFarland 2010) and Tepehua (Herzog 1987; Watters 1988; Smythe 2003; Kung 2005, 2006a, 2006b, 2007; Davletshin n.d.). Although Watters does not state explicitly that Tlachichilco Tepehua has ideophones, he describes the core adverbs as exhibiting "reduplication and ideophonic resonance" (1988:356) and states that the adverbial syntactic position is also the position in which "imitative sounds may occur" (1988:360); all of these behaviors are characteristic of ideophones in the previously mentioned languages. More specifically, not all previous descriptions of Totonac-Tepehua languages have employed the term ideophone. To be exact, only Huehuetla Tepehua (Herzog 1987; Kung 2005, 2006a, 2006b, 2007), Filomeno Mata Totonac (Santiago Francisco 2009; McFarland 2010), and Upper Necaxa Totonac (Beck 2007, 2008) have been described as having ideophones, and of these only Huehuetla Tepehua and Filomeno Mata Totonac include odor terms among the ideophones. Furthermore, although Beck (2007, 2008) describes Upper Necaxa Totonac as having ideophones, smell terms do not show the morphosyntactic behavior of items in this class.

It is outside the scope of the present work to argue that all the TotonacTepehua cognates presented herein are in fact ideophones; instead our intention is to collate, for the first time, existing olfactory terminology from the TotonacTepehua language family and show how a comparative perspective sheds further light onto the nature of sensory language more generally (Burenhult 
and Majid 2011). First, we provide the necessary background about the language family (3.1) followed by comparative data from Huehuetla Tepehua and seven other Totonac-Tepehua languages (3.2).

3.1. Totonac-Tepehua language family. Opinions differ on the status of the Totonac-Tepehua language family. Campbell, Kaufman and SmithStark (1986) and MacKay and Trechsel (2015) describe it as an isolate family in Mesoamerica, whereas Brown et al. (2011) include it in the larger Totozoquean language family. It is undisputed that Totonac-Tepehua has two main branches-Totonac and Tepehua-and that the Tepehua branch consists of three distinct varieties: Huehuetla Tepehua (tee) spoken in Hidalgo, Mexico (Kung 2007), classified as Southern Tepehua (Lewis et al. 2016) or tepehua del sur (INALI 2008); Pisaflores Tepehua (tpp) spoken in Veracruz, Mexico (MacKay and Trechsel 2015), classified as Northern Tepehua (Lewis et al. 2016) or tepehua del norte (INALI 2008); and Tlachichilco Tepehua (tpt) spoken in Veracruz, Mexico (Watters 1988), classified as Western Tepehua (Lewis et al. 2016) or tepehua del oeste (INALI 2008). The National Institute of Indigenous Languages in Mexico (INALI 2008) reports 7,511 speakers of Tepehua over the age of five, using 2005 national census data (INEGI 2005).

Early work on the Totonac branch suggested at least four varieties: (i) $\mathrm{Pa}$ pantla Totonac (top), spoken along the Gulf Coast of Veracruz; (ii) Northern or North-Central Totonac (tos), ${ }^{6}$ between Poza Rica, Veracruz, and northern Puebla; (iii) South-Central or Sierra Totonac (too), Sierra Norte de Puebla; and (iv) Misantla Totonac (tlc), the southernmost variety (McQuown 1990 [1940]; Smith-Stark 1983; MacKay 1999; MacKay and Trechsel 2015). Similarly, Brown et al. (2011) recognize four varieties: (i) Misantla, (ii) Northern, (iii) Sierra, and (iv) Lowland, and they point out the conflicting analyses of the specific divisions among the last three groups, which they call Central Totonac. INALI (2008), on the other hand, classifies Totonac into seven language groups: (i) South-Central Totonac (totonaco central del sur), (ii) Necaxa River Totonac (totonaco del río Necaxa; tku), (iii) Coastal Totonac (totonaco de la costa, Papantla Totonac; top), (iv) High Central Totonac (totonaco central alto, includes Filomeno Mata Totonac; tlp), (v) Totonac of the Xinolatépetl Mountain (totonaco del cerro Xinolatépetl, Huachinango, Puebla and surrounding area; tqt), (vi) North-Central Totonac (totonaco central del norte; too), and (vii) Southeastern Totonac (totonaco del sureste, Mistantla Totonac; tlc). The specific details of the linguistic classifications of this language family are not relevant to this study.

\footnotetext{
${ }^{6}$ The ISO language codes for the Totonac languages do not easily match up with the established linguistic divisions.
} 
TABLE 6

Number of Odor Terms Reported in Totonac-Tepenua Languages

\begin{tabular}{lcl}
\hline \hline Language & $\begin{array}{c}\text { Number of } \\
\text { Odor Terms }\end{array}$ & Source(s) \\
\hline Huehuetla Tepehua & 45 & $\begin{array}{l}\text { Kung 2005, 2007; Kung's database; current } \\
\text { study } \\
\text { Watters 1988 }\end{array}$ \\
Tlachichilco Tepehua & 24 & MacKay, p.c. \\
Pisaflores Tepehua & 9 & Santiago Francisco 2009; McFarland 2010; \\
Filomeno Mata Totonac & 21 & MacKay, p.c. \\
& 21 & Enríquez Andrade 2010 \\
Papantla Totonac & & Levy 1987, p.c. \\
& 23 & Aschmann 1946, 1983, 2000 \\
Sierra Totonac & 3 & MacKay, p.c. \\
Misantla Totonac & 17 & Beck 2011, p.c. \\
Upper Necaxa Totonac & &
\end{tabular}

3.2. The olfactory lexicons in Totonac-Tepehua. Although many studies of Totonac-Tepehua languages describe phonemic alternations, and many also note an ideophone word class, many of them have little to say about the olfactory domain, whether as part of the class of ideophones or not. We suspect this is likely oversight or underreporting rather than a real gap. For now, we have compiled existing published examples from Tlachichilco Tepehua, Filomeno Mata Totonac, Papantla Totonac, Upper Necaxa Totonac, and Sierra Totonac (see citations in table 6), alongside the data from the study described here in 2.2, and unpublished data on Upper Necaxa Totonac (David Beck, p.c.), Papantla Totonac (Paulette Levy, p.c.), Misantla Totonac and Filomeno Mata Totonac (Carolyn MacKay, p.c.), and Pisaflores Tepehua (Carolyn MacKay, p.c.). The Huehuetla Tepehua data showed considerable overlap between olfactory and gustatory terms, so we consider both domains for completeness. This preliminary examination produces some intriguing results, as we show below.

Table 6 provides an estimate of the number of odor terms reported in various sources. The counts treat each phonemic alternation of a similar form separately (as in table $4 ; \mathbf{2 . 2}$ ).

Our comparison of the odor terms across these languages shows that the Totonac and Tepehua languages share similar sound-symbolic phonemic alternation processes. In fact, there appear to be cognate odor terms that display both form and meaning correspondences. This is particularly striking in the data in table 7, where cognate terms for excrement and rotten meat smells are given. 
TABLE 7

Totonac-Tepehua Cognates for 'Rotten/Fecal Smell'

\begin{tabular}{|c|c|c|c|}
\hline $\begin{array}{l}\text { Cognate } \\
\text { Term }\end{array}$ & $\begin{array}{l}\text { Object Exemplars which } \\
\text { Emit This Odor }\end{array}$ & Language & Source \\
\hline p'uks & $\begin{array}{l}\text { dirty diaper, rotten meat, dead } \\
\quad \text { animal }\end{array}$ & $\begin{array}{l}\text { Huehuetla } \\
\text { Tepehua }\end{array}$ & current study \\
\hline p'uks & excrement and rotten meat & $\begin{array}{l}\text { Tlachichilco } \\
\text { Tepehua }\end{array}$ & Watters 1988 \\
\hline p'ukfa & excrement, dead animal, cedar & $\begin{array}{l}\text { Pisaflores } \\
\text { Tepehua }\end{array}$ & Carolyn MacKay, p.c. \\
\hline pưksa & $\begin{array}{l}\text { something rotten, decomposing, } \\
\text { garbage, excrement, dead or wet } \\
\text { animals }\end{array}$ & Papantla Totonac & Enríquez Andrade 2010 \\
\hline puksa & $\begin{array}{l}\text { excrement, rotten meat, pestilence, } \\
\text { dirty paws }\end{array}$ & $\begin{array}{l}\text { Filomeno Mata } \\
\text { Totonac }\end{array}$ & Santiago Francisco 2009 \\
\hline pưksa & excrement & Misantla Totonac & Carolyn MacKay, p.c. \\
\hline pưksa & $\begin{array}{l}\text { putrid, smelling of rot (meat, food, } \\
\text { propane) }\end{array}$ & $\begin{array}{l}\text { Upper Necaxa } \\
\text { Totonac }\end{array}$ & David Beck, p.c. \\
\hline
\end{tabular}

More generally, we found some close cognates in the olfactory domain across Totonac and Tepehua languages in which the forms are clearly related, and these are shown in table 8. To find these cognates, we used as a starting point groups of Huehuetla Tepehua odor terms that are formally similar. We then searched for cognate forms in other Totonac and Tepehua languages using the sources cited in table 6 . In doing so, we found many cognates in Totonac languages that were not produced by Huehuetla Tepehua speakers during the Sniffin' Sticks protocol or follow-up elicitation described in 2.2, and these terms are listed at the end of the table in rows 16-18. We have organized the table such that the odors for which we found cognates across all languages - both Tepehua and Totonac - appear at the top of the table. Rows 1 and 2 are completely filled in whereas rows 3-10 have progressively fewer cognates. Rows 11-15 show Tepehua-only cognates, and rows 16-18 have Totonac-only cognates.

As illustrated in table 8, some odor terms in Huehuetla Tepehua have cognate forms in other Totonac-Tepehua languages where both form and meaning match. There is an impressive number of correspondences here across the olfactory lexicon, making a strong case against claims that the domain of smell is ineffable. Although not all of the terms across the sample have been classified as ideophones in the original sources, many have explicitly been identified as such, which is remarkable considering the previously entertained claim that ideophones are highly malleable (Lanham 1960 as cited in Childs 1994). The longevity of these terms belies such a claim.

Although there are impressive correspondences in olfactory terms across languages, unsurprisingly not all cognate terms share meaning. For example, 
the Filomeno Mata Totonac term $t k u n k a$ is used for the following smells: raw meat, water that has been left standing for a while, broth after its first boil, egg, the edge of a blade that has not been washed very well, the edge of a machete if it has gotten wet or if it was used to cut meat, oxidized metal, or unwashed grain (Santiago Francisco 2009; McFarland 2010). However, the same term, tkunka, in Papantla Totonac is used to describe the smell of breast milk, the smell of opossum and dog, or the smell of urine or sweat (Enríquez Andrade 2010:141).

We found no cognates at all for numerous odor terms in Huehuetla Tepehua. These terms are shown in table 9 and are grouped based on the general meaning of the odor terms.

As noted earlier, many terms can be used for both olfactory and gustatory modalities. This is true also of some of the forms given in table 8. To gain better purchase on the data, we specifically pulled out the taste terms across the language sample. The shaded cells in table 10 indicate terms that can be used in both smell and taste domains $;^{7}$ unshaded cells indicate terms used for taste (according to the relevant data source). A cursory glance at table 10 reveals a striking amount of stability in cognate terms for taste.

If cognate forms across language varieties are indicators of longevity of categories, then some intriguing patterns are suggested by the data in tables 8 and 10. First, almost all languages appear to have considerable overlap in cognate forms for taste, more so than for olfaction. This suggests olfactory categories may be more variable than taste categories. Second, among the odor terms, certain categories recur. For example, there are cognate forms across Totonac-Tepehua languages used to describe the smell of rotten meat or excrement (see table 7) and a strong, unpleasant odor, which was exemplified by the edible pod and seeds from the guaxi (or guaje) tree (see hakf in table 8).

Various explanations could be entertained for the longevity of taste terms and relative instability of olfactory terms across related languages. One possibility is that these differences mirror cultural or environmental factors. If sensory vocabulary is tied to its cultural niche, then similarities found in culinary practices across the Totonac and Tepehua peoples is a possible explanation for the observed stability in the taste domain.

This line of reasoning suggests olfactory categories should also be similar across these languages: the same (or very similar) material culture properties are found in both groups, and there are very few differences in food, agriculture, technology, or ritual practices (Williams García 1963, 1972). However, that is not the case. Olfactory environments vary considerably (Majid et al.

\footnotetext{
${ }^{7}$ There are likely more cognate correspondences and more overlap between tastes and smells than shown here. Unfortunately, not all sources indicate if the terms are used for both taste and smell, and it is quite likely that terms were not checked for both domains of use. This would be a matter for future detailed investigation.
} 


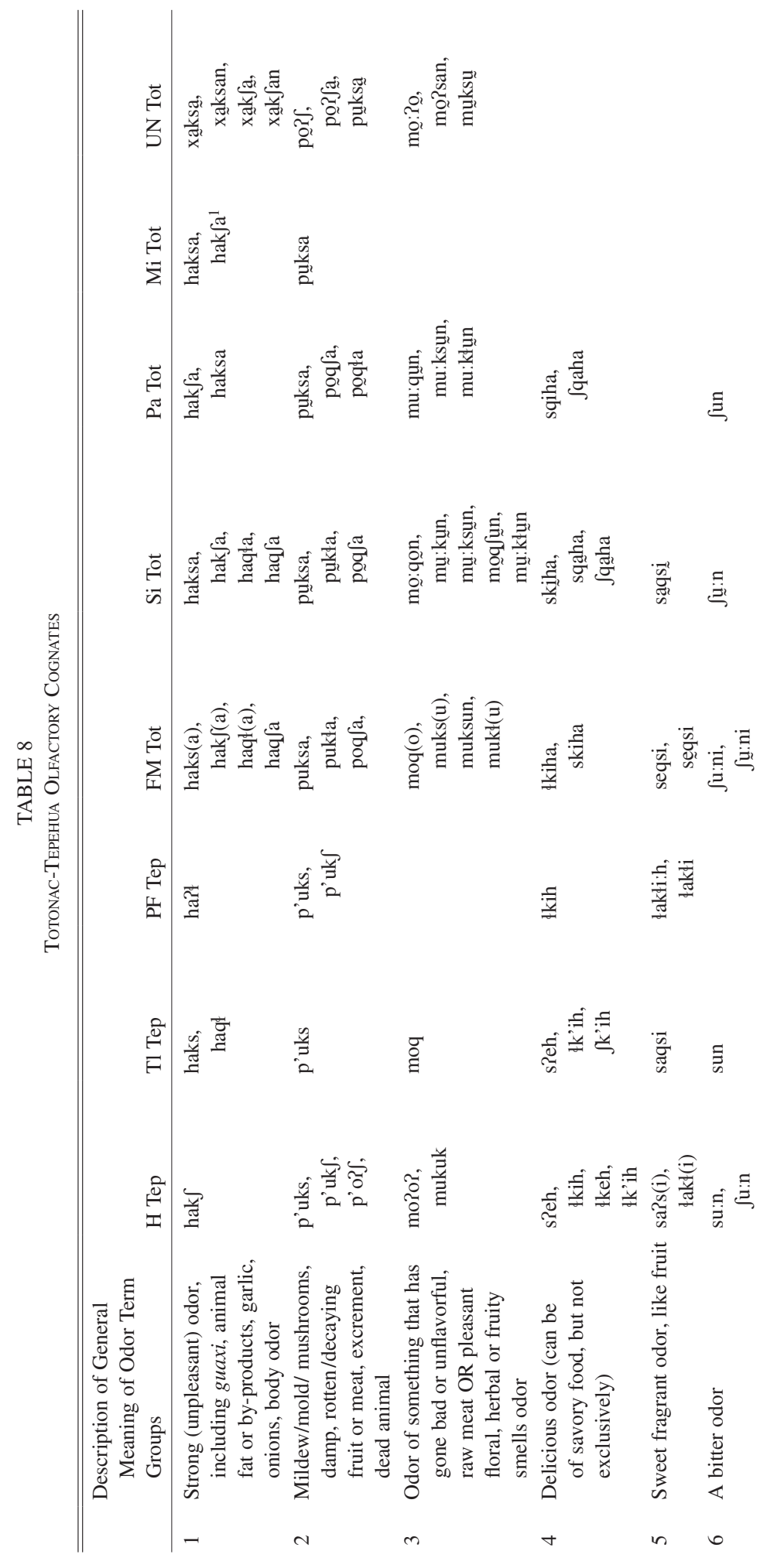




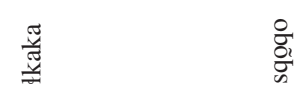

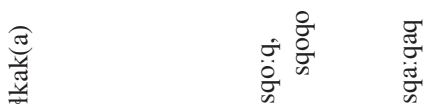
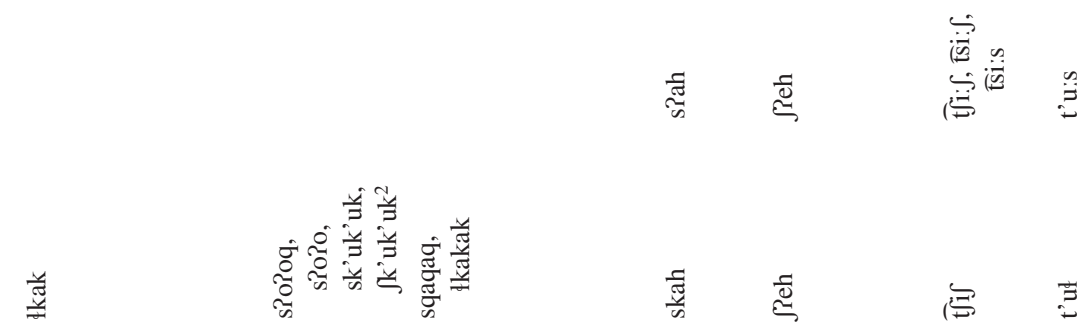

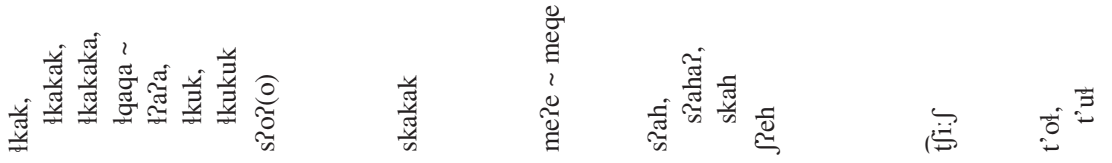
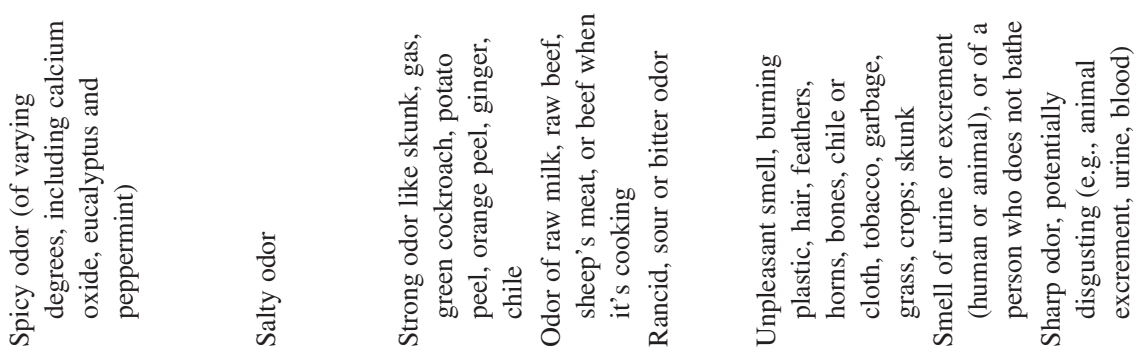

r

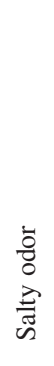

$a$

$\bigcirc=\simeq$

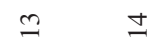




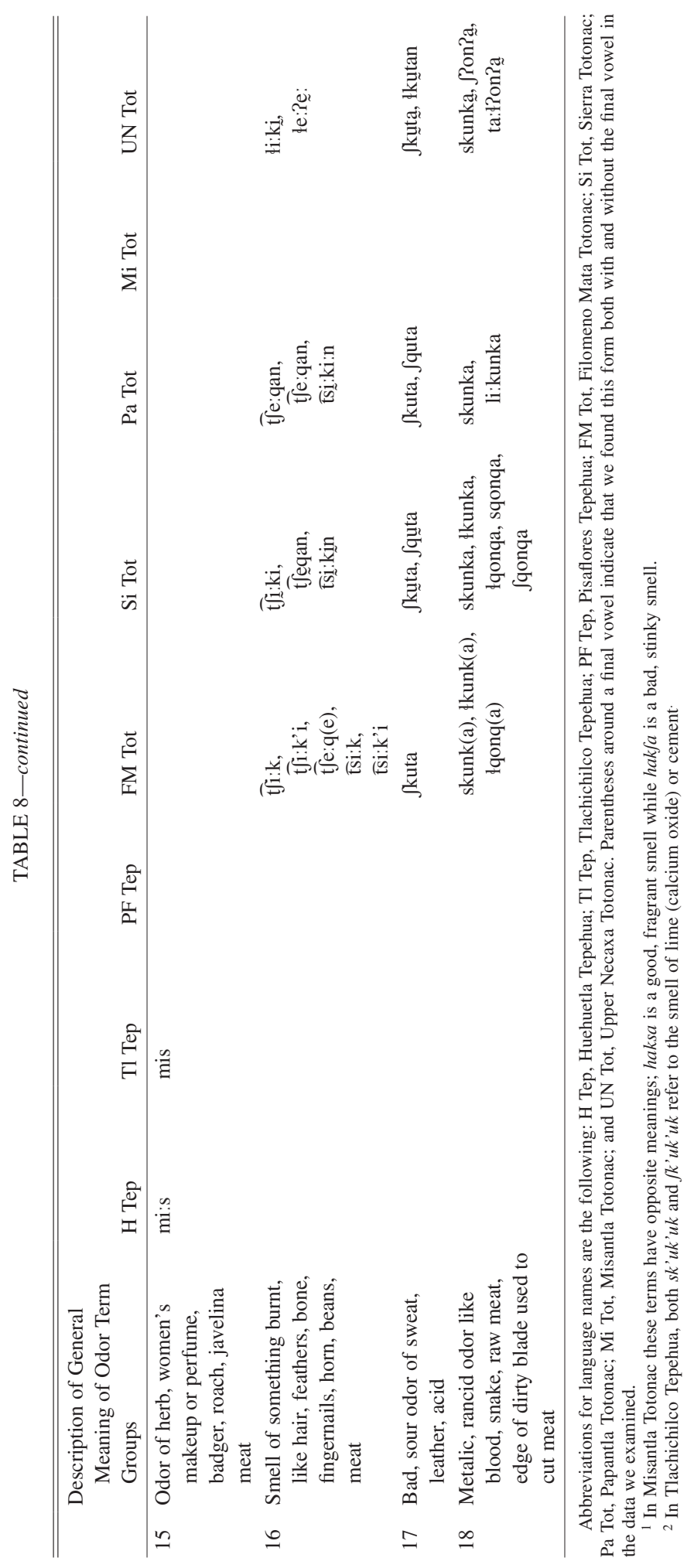


TABLE 9

Huehuetla Tepehua Odor Terms without Known Cognates

\begin{tabular}{|c|c|}
\hline Description of General Meaning of Odor Term Groups & H Tep Ideophones \\
\hline Delicious beautiful odor, floral (of varying degrees) & Puli, Pulili, k’uli, k'ulik, sk'uli \\
\hline Delicious odor & $\operatorname{kan}(\mathrm{i})$ \\
\hline A beautiful odor & k’us \\
\hline A really bad odor & di:ți \\
\hline Similar to $p^{\prime} u k s$, but not as bad, something that has gone bad & ma: $\int$ \\
\hline A disagreeable, stinky odor (e.g., dead person, excrement) & saw, ts'aw \\
\hline No gloss; response to pineapple stimulant & $\widehat{\mathrm{t} f a k t \int \mathrm{i}}$ \\
\hline No gloss; response to vinegar, soy sauce, rose stimulants & ta: \\
\hline Odor of flavored water & ţaja:w \\
\hline
\end{tabular}

2017). The odors an urban dweller is exposed to are different than those of a farmer, and a Totonac speaker living in the highlands will experience a different smellscape than that of people residing on the coast. If odor terms are fitted to their local ecology (Storch 2014; O'Meara and Majid 2016), then these differences could also shape smell lexicons and lead to greater variation in smell terminology. An alternative explanation lies not in differential environments or cultures, but in shared biology. Language and olfaction appear to be poorly linked (Olofsson and Gottfried 2015), so variation in smell terms could be the result of poor semantic coding resulting from this instable neural architecture - that is, we may see more variation in olfactory language cross-linguistically because of unstable language-olfaction connections. These different possibilities could be teased apart by more detailed examination of the physical and cultural environments in which these linguistic communities are embedded.

4. Conclusions. Olfaction has been categorized as not amenable to linguistic expression, and as such, this domain has been given little attention in linguistic documentation and description. However, recent studies have begun to shed light on elaborate olfactory lexicons in lesser-studied languages. We describe-for the first time - the rich set of odor terms of Huehuetla Tepehua. Using an odor elicitation task, as well as free-listing and interview methodologies, we found 45 distinct terms which have a semantically specific odor meaning, and which are used to refer to diverse types of odors. These range from pleasant and fragrant odors to edible and-its converse-inedible odors to rancid, rotten, or excremental odors, among others. The terms are not derived from lexical nouns referring to a particular odor source, nor to our knowledge are the terms specific to describing the smell of one particular object. These findings show that olfaction is highly 


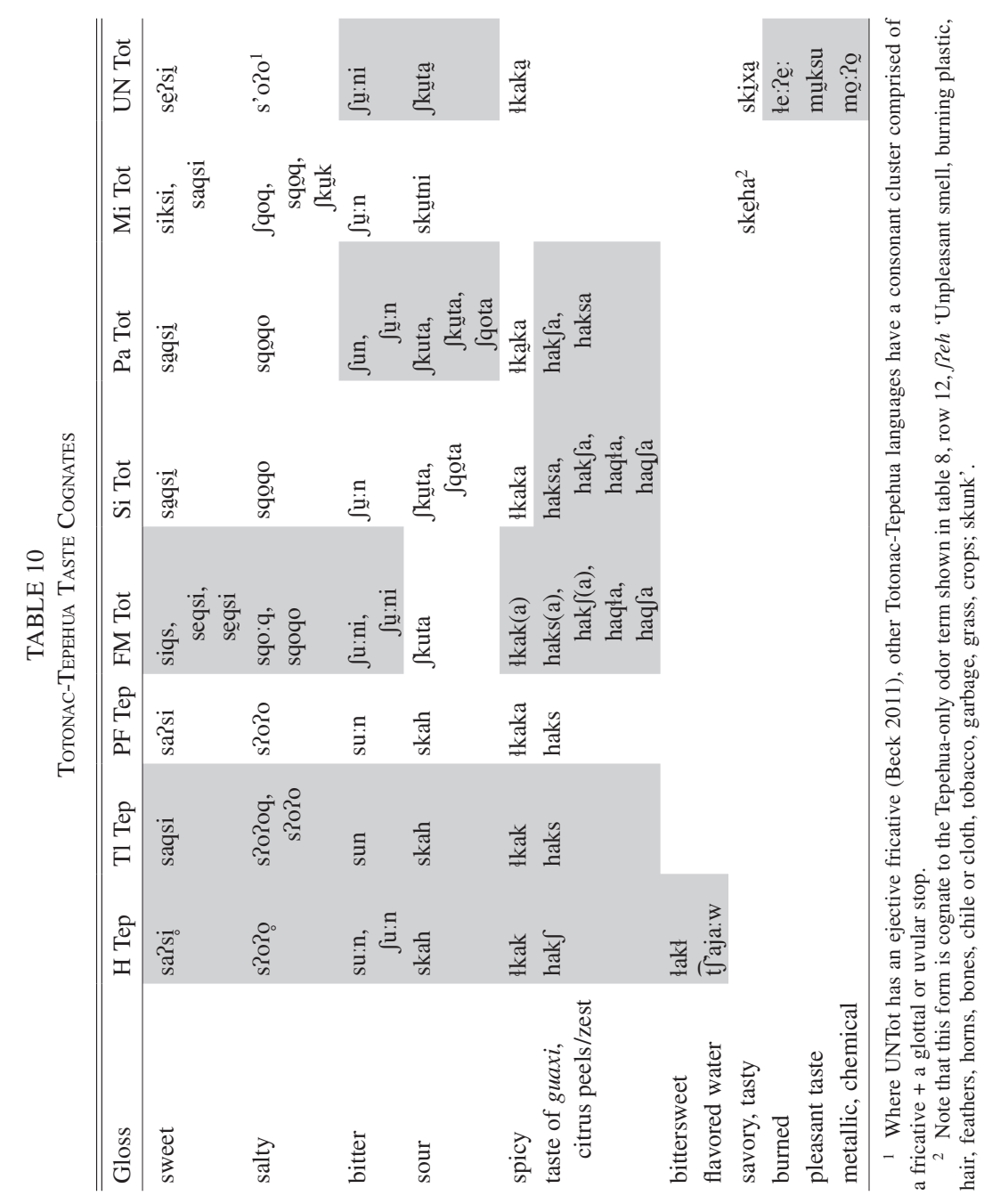


lexically codable in Huehuetla Tepehua and, as such, prove problematic for claims of olfaction being ineffable. The wider implication here is that focused multi-method elicitation can directly address claims of "rara and rarisima" in language (Plank and Filimonova 2000), suggesting an urgent need to widen the methodological toolbox for language documentation.

As more studies provide data questioning the ineffability of olfaction and the culture-specific differences between olfactory lexicons across languages (Majid 2015), we are moving closer to what a typology of odor language might look like. The Huehuetla Tepehua data presented here add to our understanding of what such a typology must consider-namely, that in some languages ideophones are loci for lexicalizing odor concepts. In the case of Huehuetla Tepehua, ideophones can stand alone as adverbs in addition to functioning as roots in derived verbs (see Kung 2007), indicating that in order to fully understand the linguistic resources speakers have at their disposal to describe smells, we must expand our lexical reach beyond verbs of perception. This has implications not only for language documentation and description efforts, but also for advancing our understanding of ideophones cross-linguistically.

Ideophones, in comparison with other word classes, are defined as being performative in nature and depictive of sensory imagery, inviting listeners to imagine a particular experience or scene depicted in the form (Nuckolls 2010; Dingemanse 2012). This might seem natural when it comes to sound or motion, but it is less obvious how olfactory ideophones can invite simulation of olfaction - that is, it is difficult to imagine what a particular smell quality ought to be solely based on the form of an ideophone (what specific, vivid smell depiction is conjured to mind from $t k u k$, for example?). Our analysis of the semantics of Huehuetla Tepehua odor terms, many of which are ideophones, suggests they do not depict specific odor qualities (i.e., they do not have diagrammatic Gestalt iconicity). Their sound-symbolic nature can indicate general qualities such as intensity and pleasantness (i.e., relative iconicity; Dingemanse 2012:659), but even this requires lexeme-specific knowledge since the same alternations can have different interpretations across roots. Our analysis suggests that different sensory modalities allow different levels of form-to-meaning mapping and different types of depiction (i.e., not depicting the quality of the percept in the case of olfaction). These findings enrich our understanding of the role depiction can play in ideophone semantics-in particular, its limitations in conveying odor percepts.

Finally, our comparative study across the closely related Totonac-Tepehua languages found that olfactory cognates have considerable longevity. In these languages there is close overlap in smell and taste vocabulary, but intriguingly, when examined by subdomain, olfactory terms appear to be more tenuous than gustatory ones. This leaves open the question of whether this variation in the olfactory domain is attributable to differences in the languages, the 
environment where they are spoken, or both. We speculate that the differences are more likely explained by the fact that humans are physically able to distinguish countless numbers of odors and that we are exposed to odors on a regular basis simply by the act of breathing, but the odors we are exposed to regularly reflect differences in local ecology. This intriguing possibility requires further investigation and paves new ground for thinking about the relationship between language, culture, and brain.

\section{REFERENCES}

AmeKA, Felix K. 2001. Ideophones and the nature of the adjective word class in Ewe. Ideophones, ed. F. K. Erhard Voeltz and Christa Kilian-Hatz, 25-48. Amsterdam: John Benjamins.

Arana Osnaya, Evangelina. 1953. Reconstrucción del proto-totonacano. Huastecos, totonacos y sus vecinos, ed. Ignacio Bernal and Eusebio Dávalos Hurtado, Revista Mexicana de Estudios Antropológicos 13(2/3):123-30. México, DF: Sociedad Mexicana de Antropología.

Aschmann, Herman P. 1946. Totonac categories of smell. Tlalocan 2:187-89.

. 1983. Vocabulario Totonaco de la Sierra. Vocabularios Indígenas 7. México, DF: Instituto Lingüístico de Verano.

. 2000. Diccionario Totonaco de la Sierra. Unpublished ms. http://www.sil.org/ resources/archives/51831.

BecK, David. 2004. Upper Necaxa Totonac. Languages of the World/Materials 432. Munich: Lincom.

. 2007. What to do with the ideophones? A problem in lexical classification from Upper Necaxa Totonac. Selected Lexical and Grammatical Issues in the Meaning-Text Theory: In honour of Igor Mel'čuk [Studies in Language Companion Series 84], ed. Leo Wanner. Philadelphia/Amsterdam: John Benjamins.

. 2008. Ideophones, adverbs, and predicate qualification in Upper Necaxa Totonac. IJAL 74(1):1-46.

. 2011. Upper Necaxa Totonac Dictionary. Berlin: Mouton de Gruyter.

Berlin, Brent, and Paul Kay. 1969. Basic Color Terms: Their Universality and Evolution. Chicago: University of Chicago Press.

Bishop, Ruth G. 1984. Consonant play in lexical sets in Northern Totonac. Summer Institute of Linguistics Mexico Workpapers 5:24-31.

Blench, Roger. 2010. The sensory world: Ideophones in Africa and elsewhere. Perception of the Invisible: Religion, Historical Semantics and the Role of Perceptive Verbs. Sprache und Geschichte in Afrika 21, ed. Anne Storch, 275-96. Cologne: Köppe.

Blench, Roger, and Selbut Longtau. 1995. Tarok ophresiology. Issues in African Linguistics: Essays in Honour of Kay Williamson, ed. E. N. Emenanjo and O. Ndimele, 340-44. Aba: National Institute for Nigerian Languages.

Brown, Cecil H., David Beck, Grzegorz Kondrak, James K. Watters, and Søren Wichmann. 2011. Totozoquean. IJAL 77(3):323-72.

Burenhult, Niclas, AND Asifa Majid. 2011. Olfaction in Aslian ideology and language. The Senses and Society 6(1):19-29.

Campbell, Lyle, Terrence Kaufman, and Thomas C. Smith-Stark. 1986. Meso-America as a linguistic area. IJAL 62(3):530-70.

Chapman, Adam. 1996. The syntax of Lao expressives. BA thesis, Australian National University, Canberra.

Childs, G. Tucker. 1994. African ideophones. Sound Symbolism, ed. Leanne Hinton, Johanna Nichols, and John J. Ohala, 178-204. Cambridge: Cambridge University Press. 
Clark, Herbert H. 2016. Depicting as a method of communication. Psychological Review 123(3):324-47.

Davletshin, Albert. n.d. Los sustantivos, adverbios y adjetivos ideofónicos en el tepehua de Pisaflores, Veracruz, México. Unpublished ms.

Dingemanse, Mark. 2011. The meaning and use of ideophones in Siwu. PhD dissertation, Radboud University, Nijmegen.

. 2012. Advances in the cross-linguistic study of ideophones. Language and Linguistics Compass 6(10):654-71.

Dingemanse, Mark, Damián Blasi, Gary Lupyan, Morten H. Christiansen, and Padraic Monaghan. 2015. Arbitrariness, iconicity, and systematicity in language. Trends in Cognitive Science 19(10):603-15.

Doke, Clement Martyn. 1935. Bantu Linguistic Terminology. London: Longmans, Green.

England, Nora. 2004. Entrando y saliendo de una posición: Palabras afectivas en Mam. Paper presented at Lengua y Mantenimiento Cultural en Mesoamérica: Un Simposio, University of Texas at Austin.

EnríqueZ AndRAde, Héctor Manuel. 2004. La categorización de olores en totonaco. Dimensión Antropológica 11(30):103-28.

- 2010. El Campo Semántico de los Olores en Totonaco. Mexico, DF: Instituto Nacional de Antropología e Historia.

Haynie, Hannah, Claire Bowern, and Hannah laPalombara. 2014. Sound symbolism in the languages of Australia. PLoS ONE 9(4):e92852.

Henderson, Robert. 2016. A demonstration-based account of (pluractional) ideophones. Proceedings of SALT 26:664-83.

Henning, Hans. 1916. Der Geruch. Leipzig, Germany: J. A. Barth. (Originally published in 1824)

Herzog, Dorothy. 1987. Ideophones in Huehuetla Tepehua. Summer Institute of Linguistics. Unpublished $\mathrm{ms}$.

Hill, Jane, and Ofelia Zepeda. 1992. Derived words in Tohono O'odham. IJAL 58(4):355-404.

Hombert, Jean Marie. 1992. Terminologie des odeurs dans quelques langues du Gabon. Pholia 7:61-65.

Hummel, T., B. Sekinger, S. R. Wolf, E. Pauli, and G. Kobal. 1997. "Sniffin' sticks": olfactory performance assessed by the combined testing of odor identification, odor discrimination and olfactory threshold. Chemical Senses 22(1):39-52.

INALI. 2008. Catálogo de las lenguas indígenas nacionales: Variantes lingüísticas de México con sus autodenominaciones y referencias geoestadísticas. Diario Oficial, January 14, 2008.

INEGI. 2005. II Conteo de Población y Vivienda, Instituto Nacional de Estadística y Geografía.

Kaufman, TerRence. 1988/2004. Sound symbolism seminar notes. Educational Materials Collection of Terrence Kaufman. The Archive of the Indigenous Languages of Latin America, www. ailla.utexas.org. Access: Public, PID ailla:137498. Accessed March 20, 2016.

Keller, Andreas, Richard C. Gerkin, Yuanfang Guan, et al. 2017. Predicting human olfactory perception from chemical features of odor molecules. Science 355(6327):820-26.

Khan, Rehan M., Chung-Hay Luk, Adeen Flinker, Amit Aggarwal, Hadas Lapid, Rafi Haddad, AND NoAm Sobel. 2007. Predicting odor pleasantness from odorant structure: Pleasantness as a reflection of the physical world. Journal of Neuroscience 27:10015-23.

Klamer, Marian. 2002. Semantically motivated lexical patterns: A study of Dutch and Kambera expressives. Language 78(2):258-86.

KulemeKa, A. T. 1995. Sound symbolic and grammatical frameworks: A typology of ideophones in Asian and African languages. South African Journal of African Languages 15(2):73-84.

Kung, Susan Smythe. 2005. Sound symbolism and expressive language in Huehuetla Tepehua. Paper presented at the Society for the Study of Indigenous Languages of the Americas Annual Meeting, Oakland, CA, January 9, 2005. Archived in the Huehuetla Tepehua Collection of 
Susan Smythe Kung, The Archive of the Indigenous Languages of Latin America, www.ailla. utexas.org. Access: public. PID ailla:241552. Accessed May 5, 2015.

. 2006a. El lenguaje expresivo en el tepehua de Huehuetla: Entre simbolismo de sonido y palabras afectivas. Paper presented at the VIII Congreso Nacional de la Asociación Mexicana de Lingüística Aplicada y la Universidad de las Américas—Puebla; Cholula, Puebla, México, May 18, 2006. Archived in the Huehuetla Tepehua Collection of Susan Smythe Kung, The Archive of the Indigenous Languages of Latin America, www.ailla.utexas.org.Access: public. PID ailla:139078. Accessed May 5, 2015.

. 2006b. Simbolismo de sonido y el lenguaje expresivo en el tepehua de Huehuetla. Memorias del VIII Encuentro Internacional de Lingüística en el Noroeste, ed. María del Carmen Morúa, vol. 3, 331-54. Hermosillo, Sonora, México: Editorial Universidad de Sonora. . 2007. A descriptive grammar of Huehuetla Tepehua. PhD dissertation, University of Texas at Austin. Archived in the Huehuetla Tepehua Collection of Susan Smythe Kung, The Archive of the Indigenous Languages of Latin America, www.ailla.utexas.org.Access: public. PID ailla:134797. Accessed May 5, 2015.

Kung, Susan, and Carolyn O'Meara. 2014. Olfactory lexicon data collection 2014: Notebook1. pdf. The Archive of the Indigenous Languages of Latin America, www.ailla.utexas.org. Access: Public, PID ailla:256243. Accessed March 20, 2016.

Lanham, L. W. 1960. The comparative phonology of Nguni. PhD dissertation, University of Witwatersrand.

Lee, Amy Pei-Jung. 2014. Lexical categories and conceptualization of olfaction in Amis. Language and Cognition 7(3):1-30.

- 2017. Ideophones, interjections, and sound symbolism in Seediq. Oceanic Linguistics 56(1):181-209.

Levinson, Stephen C., And Asifa Majid. 2014. Differential ineffability and the senses. Mind and Language 29:407-27.

Levy, Paulette. 1987. Fonología del totonaco de Papantla, Veracruz. Mexico, DF: Universidad Nacional Autónoma de México.

2004. Adjectives in Papantla Totonac. Adjective Classes: A Cross-Linguistic Typology, ed. R. M. W. Dixon and Alexandra Y. Aikhenvald, 147-76. Oxford: Oxford University Press.

Lewis, M. Paul, Gary F. Simons, and Charles D. Fennig (eds.). 2016. Ethnologue: Languages of the World, Nineteenth edition. Dallas: SIL International. Online version: http://www.ethnologue.com.

MacKay, Carolyn. 1999. A Grammar of Misantla Totonac. Salt Lake City: University of Utah Press.

Mackay, Carolyn J., and Frank R. Trechsel. 2015. Totonac-Tepehua genetic relationships. Amerindia 37(2):121-57.

MaJid, AsIFa. 2015. Cultural factors shape olfactory language. Trends in Cognitive Sciences 19(11):629-30.

MAJID, AsIFA (ed.). 2007. Field Manual, vol. 10. Nijmegen: Max Planck Institute for Psycholinguistics.

Majid, Asifa, And Niclas Burenhult. 2014. Odors are expressible in language, as long as you speak the right language. Cognition 130(2):266-70.

Majid, Asifa, and Nicole Kruspe. 2018. Hunter-gatherer olfaction is special. Current Biology 28(3):409-13.

Majid, Asifa, Laura Speed, Ilua Croijmans, and Artin Arshamian. 2017. What makes a better smeller? Perception 46(3-4):406-30.

Majid, Asifa, Sean Roberts, Ludy Cilissen, et al. 2018. Differential coding of perception in the world's languages. Proceedings of the National Academy of Sciences 115(45):11369-76.

McFarland, Teresa. 2010. Ideophones and templatic morphology in Totonac. Rara and Rarissima: Documenting the Fringes of Linguistic Diversity, ed. Jan Wohlgemuth and Michael Cysouw, 235-46. Berlin: de Gruyter. 
McQuown, Norman. 1990. [1940]. Gramática de la lengua totonaca (Coatepec, Sierra Norte de Puebla). Mexico, DF: Universidad Nacional Autónoma de México.

Mithun, Marianne. 1982. The synchronic and diachronic behavior of plops, squeaks, croaks, sighs, and moans. IJAL 48(1):49-58.

Nichols, Johanna. 1971. Diminutive consonant symbolism in western North America. Language 47:826-48.

NucKolls, JANIs. 2010. Lessons from a Quechua Strongwoman: Ideophony, Dialogue and Perspective. Tucson: University of Arizona Press.

O’Meara, Carolyn, and Asifa Majid. 2016. How changing lifestyles impact Seri smellscapes and smell language. Anthropological Linguistics 58(2):107-31.

Olofsson, Jonas K., and Jay A. GotTFried. 2015. The muted sense: Neurocognitive limitations of olfactory language. Trends in Cognitive Sciences 19:314-21.

Perniss, Pamela, Robin L. Thompson, and Gabriella Vigliocco. 2010. Iconicity as a general property of language: Evidence from spoken and signed languages. Frontiers in Psychology 1:227. doi:10.3389/fpsyg.2010.00227.

Plank, Frans, and Elena Filimonova. 2000. The universals archive: A brief introduction for prospective users. Sprachtypologie und Universalienforschung 53(1):109-23.

Ratliff, Martha. 1992. Meaningful Tone: A Study of Tonal Morphology in Compounds, Form Classes, and Expressive Phrases in White Hmong. DeKalb: Northern Illinois University Press.

Rivlin, Robert, and Karen Gravelle. 1984. Deciphering the Senses. New York: Simon and Schuster.

Samarin, William J. 1967. Determining the meaning of ideophones. Journal of West African Languages 4(2):35-41.

Santiago Francisco, José. 2009. Colores y olores: un estudio lingüístico entre los totonacos de Filomeno Mata, Veracruz. BA thesis, Universidad Veracruzana, Veracruz.

SAPIR, EDWARD. 1911. Diminutive and augmentative consonant symbolism in Wishram. Handbook of American Indian Languages, Bureau of American Ethnography Bulletin 40, Part 1:638-46. Washington, DC.

ShePHerd, GlenN M. 2006. Smell images and the flavour system in the human brain. Nature 444(7117):316-21.

Smith, Barry C. 2012. Perspective: Complexities of flavour. Nature 486(7403):S6. doi. org/10.1038/486S6a.

Smith-Stark, Thomas C. 1983. Estudios léxico-estadísticos de la familia totonaca. Unpublished ms. Colegio de México. Archived in The Works of Thomas Cedric Smith Stark collection, The Archive of the Indigenous Languages of Latin America, www.ailla.utexas.org. PID ailla: 243842. Accessed November 19, 2017.

Smoll, LaetiTia. 2015. Ideophones in Katuena (Tunayana): A Cariban Language of the Amazon Basin. Saarbrücken, Germany: Lambert Academic.

Smythe, Susan. 2000. Vocalic and uvular phonemes in Huehuetla Tepehua: The acoustic evidence. Unpublished ms. University of Texas at Austin. Archived in the Huehuetla Tepehua Collection of Susan Smythe Kung, The Archive of the Indigenous Languages of Latin America, www. ailla.utexas.org. Access: Public. PID ailla:134974. Accessed May 5, 2015.

. 2003. Reconstructing lost phonemes in Huehuetla Tepehua using "affectionate speech." Texas Linguistic Forum 45. Proceedings of the Tenth Annual Symposium about Language and Society-Austin, April 12-14, 2002, ed. Inger Mey, Ginger Pizer, Hsi-Yao Su and Susan Szmania, 167-76. University of Texas at Austin.

Speed, Laura, and Asifa Majid. 2018. An exception to mental simulation: No evidence for embodied odor language. Cognitive Science 42(4):1146-78.

Sperber, DAn. 1975. Rethinking Symbolism (A. L. Morton, trans.). Cambridge: Cambridge University Press. (Original work published 1974). 
Storch, AnNe. 2004. Haptische, visuelle und olfaktorische Sprachen: Westnilotische Wahrnehmungen. Afrikanistik Online. https://www.afrikanistik-aegyptologie-online.de/archiv/2004/45. Accessed September 3, 2018.

. 2013. Knowing, smelling and telling tales in Luwo. Perception and Cognition in Language and Culture, ed. A. Aikhenvald and A. Storch, 47-68. Leiden: Brill.

. 2014. A Grammar of Luwo: An Anthropological Approach. Amsterdam: John Benjamins.

Storch, Anne, and Rainer Vossen. 2006. Odours and colours in Nilotic: Comparative case studies. Proceedings of the 8th Nilo-Saharan Linguistics Colloquium, ed. D. L. Payne and M. Reh, 223-40. Köln: Rüdiger Köppe.

Svantesson, Jan-Olof. 2017. Sound symbolism: The role of word sound in meaning. Wiley Interdisciplinary Reviews: Cognitive Science 8(5):e1441.

Tufvesson, Sylvia. 2007. Expressives. Field Manual, vol. 10, ed. A. Majid, 53-58. Nijmegen: Max Planck Institute for Psycholinguistics.

ـ 2011. Analogy-making in the Semai sensory world. Senses and Society 6(1):86-95.

Ultan, Russell. 1978. Size-sound symbolism. Universals of Human Language, vol. 2: Phonology, ed. Joseph H. Greenberg, 525-67. Stanford: Stanford University Press.

van Beek, Walter E. A. 1992. The dirty smith: Smell as a social frontier among the Kapsiki/Higi of north Cameroon and north-eastern Nigeria. Africa 62(1):38-58.

Voeltz, Erhard Friedrich Karl, and Christa Kilian-Hatz (eds.). 2001. Ideophones. Typological Studies in Language, vol. 44. Amsterdam: John Benjamins.

Watters, James K. 1988. Topics in Tepehua grammar. PhD thesis, University of California, Berkeley.

Westermann, Diedrich Hermann. 1927. Laut, Ton und Sinn in Westafrikanischen Sudansprachen. Festschrift Meinhof, 315-28. Hamburg: L. Friederichsen.

. 1937. Laut und Sinn in einigen Westafrikanischen Sprachen. Archiv für Vergleichende Phonetik 1:154-72, 193-211.

WILKINS, DAVID P. 1981. Towards a theory of semantic change. Honors thesis, Australian National University, Canberra.

Williams García, Roberto. 1963. Los Tepehuas. Xalapa, Veracruz: Universidad Veracruzana.

. 1972. Mitos Tepehuas. México, DF: Secretaría de Educación Pública.

Wnuk, Ewelina, And Asifa Majid. 2014. Revisiting the limits of language: The odor lexicon of Maniq. Cognition 131(1):125-38.

YeshuRun, YaARA, And NoAm Sobel. 2010. An odor is not worth a thousand words: From multidimensional odors to unidimensional odor objects. Annual Review of Psychology 61:219-41. 